\title{
El Régimen jurídico-administrativo de tutela y protección social de personas $\operatorname{adultas}^{1}$
}

\author{
Francisco Favier López Fernández \\ Doctor en Derecho Administrativo \\ Universidad de Almería ${ }^{2}$
}

\begin{abstract}
SUMARIO: I. INTRODUCGIÓN. 1. La Administración pública en la protección de personas con necesidades sociales. A. La protección de colectivos vulnerables en perspectiva histórica. B. Grupo normativo regulador. C. La acción social como fundamento de actuación administrativa. 2. Las personas adultas como personas incapaces. II. LA NECESIDAD DE INTEGRAR LA INCAPACIDAD EN OTRAS INSTITUCIONES JURÍDICO-ADMINISTRATIVAS. 1. Incapacidad y discapacidad. 2. Incapacidad y dependencia. 3. Las personas adultas como titulares de derechos y obligaciones en el ámbito social. III. ¿QUÉ ENTIDADES PARTICIPAN EN LA TUTELA DE PERSONAS ADULTAS?. 1. Administración pública. 2. Entidades privadas y el requisito de ausencia de lucro. 3. Funciones y competencias. IV. INTERVENGIÓN ADMINISTRATIVA EN LA PRESTACIÓN DE REGURSOS SOCIALES. 1. Recursos sociales frente a la incapacidad. A. Prestaciones de servicio. B. Prestaciones económicas. 2. El sometimiento de las entidades prestadoras de recursos a la actividad limitadora de la Administración pública. V. CONSIDERACIONES FINALES.
\end{abstract}

${ }^{1}$ Este artículo de investigación se encuadra dentro del Proyecto de Investigación I+D: La reconstrucción del Sistema Nacional de Salud: Gestión, Personal y E-Salud (DER2013-48416-C2-R), concedido por el Ministerio de Economía y Competitividad del Gobierno de España, y dirigido por el Prof. Dr. Juan Francisco PÉREZ GÁLVEZ, Catedrático de Derecho Administrativo, de la Universidad de Almería. Asimismo, este trabajo es el resultado de la docencia impartida en el Curso de «Experto en Protección y Tutela de Personas Adultas», organizado por la Facultad de Derecho de la Universidad de Almería para el curso académico 2014/2015.

${ }^{2}$ Miembro del Grupo de Investigación «Ciencia y Derecho público en el siglo XXI», dirigido por el Prof. Dr. Juan Francisco PÉREZ GÁLVEZ, Catedrático de Derecho Administrativo, de la Universidad de Almería. 
RESUMEN: En esta investigación se estudia el ámbito de protección de las personas adultas. Delimitaré quiénes componen este colectivo vulnerable y por qué es precisa la intervención de la Administración pública en su protección. Asimismo analizaré qué clase de entidades de acción social son las que participan en este ámbito, bien tutelando a las personas adultas, bien como entidades prestadoras de recursos sociales. En este último caso, se estudiará brevemente no sólo el conjunto de prestaciones sociales destinadas a este sector sino los requisitos jurídico-administrativos que han de cumplir y son exigidos por las normas reguladoras de acción social.

PALABRAS CLAVE: incapacidad, personas adultas, tutela, recursos sociales.

ABSTRACT: In this research, the scope of protection of adults is studied. First outline who make up this vulnerable group and why it needs the intervention of the public administration in its protection. I also discuss what kind of social action organizations they are involved in this field, either mentoring to adults, as well as organizations providing social resources. In the latter case, we briefly examine not only the set of social benefits for the sector but the legal and administrative requirements to be met and are required by the rules of social action.

KEYWORDS: disability, adult, guardianship, social resources.

\section{INTRODUCGIÓN}

\section{La Administración pública en la protección de personas con necesidades sociales}

A lo largo de la Historia, la sociedad no ha sido capaz de dar respuesta adecuada a las distintas necesidades sociales que se han originado. Esto ha provocado una preocupación responsable de los diferentes poderes públicos que, desde el ámbito de sus competencias, han asumido como propias ciertas responsabilidades y compromisos con el objetivo de satisfacer las necesidades originadas, fundamentalmente, por las desigualdades sociales entre la población.

El Derecho ${ }^{3}$ nunca ha sido ajeno a tales circunstancias, más bien todo lo contrario, resulta ser el cauce normal para establecer una regulación eficaz en el que se constata imprescindible la intervención de la Administración pública ${ }^{4}$. Más en con-

${ }^{3}$ Vide GUASP, J. Derecho, Imprenta Gráficas Hergón, Madrid, 1971, pp. 500-501.

4 Vide MORALES, J. "Estado social y privatizaciones", Cuadernos de Relaciones Laborales, 13, (1998), p. 67. 
creto, su actuación se desarrolla a través de la acción social que, entre otras cuestiones, permite sistematizar un conjunto ordenado de normas jurídicas que regulan este ámbito de actuación.

\section{A. La protección de colectivos vulnerables en perspectiva histórica}

La protección de la Administración pública frente a las necesidades sociales no es un fenómeno nuevo. Y aunque esta protección no siempre ha existido tal y como la conocemos hoy en día, y ni muchos menos obedece a los principios sobre los que actualmente se apoya, los poderes públicos han experimentado a lo largo de los siglos un interés manifiesto en la ayuda de quienes menos recursos siempre han tenido.

Si en la Edad Media la protección pública de los más necesitados era inexistente, ya que las manifestaciones de ayuda se fundamentaban en la caridad cristiana ${ }^{5}$ (como la limosna y el hospedaje ${ }^{6}$ ), es en la Edad Moderna cuando se sientan las bases de lo que con el paso del tiempo será una organización pública de atención a los más necesitados. Durante el siglo XIX se produce el primer plan organizativo de beneficencia pública, al publicarse los principales hitos legislativos que justifican su fundamento y desarrollo. Me refiero a la Constitución Española de 1812 y las Leyes de Beneficencia de 1822 y de 18497. La intervención administrativa a través de estas normas sienta sus bases en el art. 13 de la Constitución Española de 1812, al establecer que el objeto del Gobierno «es la felicidad de la Nación, puesto que el fin de toda sociedad política no es otro que el bienestar de los individuos que la componen» ${ }^{8}$. Además en los arts. 321 y 335, se concretan las competencias que la Constitución le encomienda a las Entidades locales, cuyo desarrollo propició años más tarde, la publicación de las Leyes de Beneficencia de 1822 y 1849, donde se estableció la primera

${ }^{5}$ Vide: ARENAL, C. La beneficencia, la filantropía y la caridad, Imprenta del Colegio de Sordomudos y de Ciegos, Madrid, 1861, pp. 10 y 43; ARIAS MIRANDA, J. Reseña histórica de la beneficencia española, Imprenta del Colegio de Sordomudos y Ciegos, Madrid, 1862, pp. 75-76.

${ }^{6}$ Vide: ARIAS MIRANDA, J. (1862): 9 y 96; LÓPEZ ALONSO, C. "La acción pública no estatal", en AA.VV., Historia de la Acción Social Pública en España. Beneficencia y previsión, Ministerio de Trabajo y Asuntos Sociales, 1990, p. 4; ALONSO SECO, J.M. y GONZALO GONZÁLEZ, B. La Asistencia Social y los Servicios Sociales en España, Ministerio de la Presidencia, Madrid, 2000, p. 26; GARCÉS FERRER, J. Administración social pública. Bases para el estudio de los servicios sociales, Tirant Lo Blanch, 1992, p. 38.

${ }^{7}$ Vide LÓPEZ FERNÁNDEZ, F.J. "La acción social en la Constitución española de 1812 y su posterior legalización a través de medidas de carácter público", Revista de la Asociación Internacional de Derecho Administrativo, 10, (2011), pp. 343-382.

${ }^{8}$ Vide HERRERA GÓMEZ, M. Los orígenes de la intervención estatal en los problemas sociales, Escuela Libre Editorial, Madrid, 1999, pp. 166-169. Este autor entiende que debemos identificar el «bienestar» proclamado por la Constitución Española de 1812 como cuestiones de orden interior. 
clasificación de establecimientos de beneficencia ${ }^{9}$ y se regulaban los derechos y obligaciones de los usuarios, en definitiva, el desarrollo de un servicio público ${ }^{10}$ prestado por la Administración pública al entender que dichas actividades o servicios son indispensables y esenciales para la comunidad (razones de orden y salud pública justificaron la pertinente acción del Estado $\left.{ }^{11}\right)$.

También es importante destacar en relación al tema que nos ocupa, el Real Decreto de 14 de marzo de 1899, que reorganizó y refundió los servicios de beneficencia particular ${ }^{12}$ y general. A través de esta disposición se otorgaba al Gobierno diversas competencias con la intención de tutelar las fundaciones benéficas particulares, para que fuesen cumplidas las voluntades de los fundadores. Estas fundaciones, como más adelante veremos, cobran en la actualidad un papel protagonista en la protección y tutela de las personas adultas y, sin embargo, hunden sus raíces en el siglo XIX. De forma específica, este Real Decreto prescribe: «Eran instituciones de beneficencia los establecimientos o asociaciones permanentes destinados a la satisfacción gratuita de necesidades intelectuales o físicas» (art. 2). Sobre estas entidades, el poder público desarrollaba importantes funciones de protectorado, interviniendo a través de funciones de tutela, inspección e investigación, sanción y con una gran capacidad de transformar y extinguir o crear fundaciones para el caso de incumplimiento de la normativa aprobada.

El paso del tiempo hizo que durante el siglo XX, se transformara la beneficencia anterior en una nueva institución como la asistencia social, que con perspectiva de futuro, nació de la solidaridad y de la intención de resolver mediante diferentes modos de actuación las causas reales que producen el desamparo de ciertos sectores sociales $^{13}$. Dicha solidaridad se manifestará en el cambio de los objetivos perseguidos

9 Vide GÓMEZ DE LA SERNA, P. Instituciones del Derecho Administrativo Español, Tomo II, Imprenta de D. Vicente de Zalama, Madrid, 1843, pp. 265-287. Vide PÉREZ GÁLVEZ, J.F. La Organización Nacional de Ciegos Españoles ONCE: (Corporación de derecho público, de carácter social), Fundación ONCE, Madrid, 2006, pp. 75-92. Este autor señala que la intervención administrativa, se manifestaba en la reconversión de establecimientos de beneficencia de carácter particular, en establecimientos públicos, mediante las correspondientes indemnizaciones a los patronos de los mismos.

${ }^{10}$ Un estudio sobre su evolución e implantación en nuestro país, puede seguirse en Vide MORENO REBATO, M. Régimen jurídico de la Asistencia Social en España, Ministerio de Trabajo y Asuntos Sociales, Madrid, 2002, pp. 94-114.

11 Vide AZNAR LÓPEZ, M. "En torno a la beneficencia y su régimen jurídico", Revista española de Derecho Administrativo, 92, (1996), pp. 555-565.

12 Vide BELTRÁN AGUIRRE, J.L. El Régimen jurídico de la acción social pública, Instituto vasco de Administración Pública, Bilbao, 1992, p. 94.

13 Vide JORDANA DE POZAS, J. "El movimiento asociativo y la asistencia social", en AA.VV., Problemas fundamentales de beneficencia y asistencia social, Ministerio de Gobernación, Madrid, 1967, pp. 157-159. 
por los poderes públicos al centrar su atención e intervención no sólo en los pobres o indigentes sino en todos los sectores con necesidades sociales.

\section{B. Grupo Normativo Regulador}

El ámbito de la acción social es enormemente complejo, pues está compuesto por una gran variedad de sectores y, en consecuencia, de normas jurídicas que regulan sus ámbitos de actuación. Atendiendo al ámbito de protección y tutela de personas adultas, voy a destacar las principales normas jurídicas que desde los diferentes ordenamientos jurídicos, fundamentan la actuación de los poderes públicos.

A nivel internacional debe citarse, en primer lugar, la Declaración Universal de Derechos Humanos ${ }^{14}$ en cuyo art. 25 declara el derecho de toda persona a «un nivel adecuado que le asegure, así como a su familia, la salud y el bienestar, y en especial la alimentación, el vestido, la vivienda, la asistencia médica y los servicios sociales necesarios». También añade el derecho de todo ser humano «al reconocimiento de su personalidad jurídica» (art. 6). En segundo lugar, el Pacto Internacional de Derechos Económicos, Sociales y Culturales ${ }^{15}$, que con vocación plenamente jurídica, refuerza el contenido anterior de la Declaración Universal de Derechos Humanos al reproducir esos mismos postulados (art. 11), y reconoce el derecho de toda persona «al disfrute del más alto nivel posible de salud física y mental» (art. 12). En tercer lugar, la Declaración sobre el Progreso y el Desarrollo en lo Social ${ }^{16}$, que no sólo reafirma los derechos hasta ahora citados, sino que compele a los poderes públicos nacionales en «la protección de los derechos y la garantía del bienestar de los niños, ancianos e impedidos y la protección de las personas física o mentalmente desfavorecidas» [(art. 11.c)]. En último lugar, quiero mencionar la Convención Internacional de Naciones Unidas sobre los Derechos de las Personas con Discapacidad ${ }^{17}$, en el que los países se obligan a prohibir «toda discriminación por motivos de discapacidad» y a garantizarles «protección legal igual y efectiva contra la discriminación por cualquier motivo» (art. 5. 1 y 2). La igualdad que se proclama es efectiva en todas las facetas de la vida incluidas las referidas a las tomas de decisiones, donde de forma específica se refiere a la capacidad jurídica de las personas con discapacidad (art. 12).

${ }^{14}$ Aprobada por la Asamblea General de las Naciones Unidas el 10 de diciembre de 1948.

${ }^{15}$ Adoptado el 16 de diciembre de 1966, y ratificado por España mediante Instrumento de 13 de abril de 1977.

16 Proclamada mediante Resolución 2542 (XXIV), de 11 de diciembre de 1969.

${ }^{17}$ Adoptado el 13 de diciembre de 2006 y ratificado por España mediante Instrumento de 21 de abril de 2008 . 
A nivel supraestatal o comunitario, he de indicar, previamente, que la política social en la Unión Europea adolece de la importancia que siempre ha tenido la política económica o monetaria, estando relegada a un segundo plano ${ }^{18}$. No obstante, voy a destacar dos instrumentos jurídicos relacionados con esta materia. En primer lugar, la Carta Social Europea ${ }^{19}$, que recoge los derechos de toda persona inválida a la formación profesional y a la readaptación profesional social, sea cual fuere el origen y naturaleza de su invalidez (art. 13), el de toda persona de edad avanzada al derecho a la protección social (art. 23); y, en general, el de toda persona a la protección contra la pobreza y la exclusión social (art. 30) y a beneficiarse de servicios de bienestar social (art. 14) ${ }^{20}$. En segundo lugar, la Carta de los Derechos Fundamentales de la Unión Europea ${ }^{21}$, que con valor jurídicamente vinculante para todos los Estados miembros ${ }^{22}$, reconoce los derechos de las personas mayores (art. 25) y la integración de las personas discapacitadas (art. 26).

18 Vide: BARRANCO VELA, R. "Reflexiones y comentarios en torno a la contribución de los usuarios en el costo y mantenimiento de determinadas prestaciones en la Ley de Servicios Sociales de Andalucía", Revista andaluza de Trabajo y Bienestar Social, 32, (1994), p. 70; MUÑOZ MACHADO, S., MESTRE DELGADO J.F., y ÁLVAREZ GARCÍA, V. "La europeización de las garantías de los derechos y la universalización en Europa de algunas políticas de bienestar", en MUÑOZ MACHADO, S., GARCÍA DELGADO, J.L., y GONZÁLEZ SEARA, L., (directores), Las estructuras del bienestar en Europa, Escuela Libre Editorial, Madrid, 2000, p. 374.

${ }^{19}$ Adoptada el 18 de octubre de 1961 por el Consejo de Europa y ratificada por España mediante Instrumento de 6 de mayo de 1980. La Carta Social Europea (revisada) adoptada el 23 de octubre de 2000, aún no ha sido ratificada por las Cortes Generales. Si bien carece de valor normativo en nuestro ordenamiento jurídico, sí considero que su valor indicativo es sustancial: en primer lugar, porque la propia firma del Tratado ya impone ciertas obligaciones a los Estados participantes que derivan del propio Tratado y, en segundo lugar, la Carta Social Europea revisada de 1996 supone una ampliación de la de 1961, y que ésta continúa plenamente vigente y por lo tanto vincula jurídicamente al Estado español. Vide LEMA TOMÉ, M., "La reforma sanitaria en España: especial referencia a la población inmigrante en situación administrativa irregular", Revista en Cultura de la Legalidad, 5, (2014), pp. 103-104.

${ }^{20}$ COSTA, J.P. "La Carta Social Europea”, en MUÑOZ MACHADO, S., GARCÍA DELGADO J.L., y Luis GONZÁLEZ SEARA, L. (2000): 436-438.

${ }^{21}$ Proclamado en la Cumbre de Niza celebrada el 7 diciembre de 2000. Vide: ANDRÉS SAÉNZ DE SANTA MARÍA, P. "La Carta de los Derechos Fundamentales de la Unión Europea en la práctica española", Revista de Derecho de la Unión Europea, 15, (2008), pp. 233-254; GIL y GIL, J.L. "Los derechos sociales en la Carta de los Derechos Fundamentales de la Unión Europea", Cuadernos electrónicos de filosofia del derecho, 5, (2002).

${ }^{22}$ El contenido efectivo de la Carta de los Derechos Fundamentales de la Unión Europea es el texto adaptado que se proclamó en Estrasburgo, el 14 de diciembre de 2007. Desde entonces este documento tiene el mismo valor jurídico que los Tratados, si bien su ámbito de aplicación queda relegado, respecto a los Estados miembros, «únicamente cuando apliquen el Derecho de la Unión» y, respecto a los órganos e instituciones de la Unión, siempre lo aplicarán «respetando el principio de subsidiariedad». 
A nivel interno destaco, por un lado, los preceptos contenidos en el ordenamiento jurídico estatal presidido por los derechos y principios recogidos en la Constitución Española de 1978. El intervencionismo público se fundamenta en el reconocimiento constitucional que del Estado social vincula y obliga a los poderes públicos a través del art. 1.1. $\mathrm{CE}^{23}$, art. 9.2 CE (igualdad sustancial), art. $14 \mathrm{CE}$ (igualdad formal), art. $10 \mathrm{CE}$ (interpretación según los postulados de la DUDH) y los principios configuradores de intervención administrativa ${ }^{24}$ contenidos en el Capítulo III del Título I de la CE (arts. 39-52 CE), especialmente, los artículos dedicados a la protección tanto de las personas con discapacidad (art. $49 \mathrm{CE}$ ) como de la tercera edad (art. $50 \mathrm{CE})^{25}$.

Por otro lado, el ámbito autonómico viene a desarrollar y completar el ámbito de actuación y protección de las personas con necesidades sociales. Ello se debe a dos motivos: en primer lugar, la acción social es una competencia que ha sido asumida por todas las CCAA como exclusiva, a través de sus Estatutos de Autonomía, en virtud de lo dispuesto en el art. 148.1.20 $\mathrm{CE}^{26}$; en segundo lugar, y como consecuencia de lo anterior, se puede constatar la existencia de diecisiete sistemas públicos de acción social, con una norma cabecera de grupo normativo (ley de servicios sociales) y, un complejo y variado conjunto de normas jurídicas, que en virtud de la competencia asumida, regularán sobre la totalidad de sectores que componen este ámbito, como personas mayores, dependientes, personas con discapacidad, etc ${ }^{27}$.

Finalmente, a nivel local, las competencias de las entidades locales han venido siendo determinadas tanto por las normas básicas dictadas sobre régimen local a nivel estatal, como por las normas específicas que en materia social se han dictado en

${ }^{23}$ Vide: STC 18/1984, de 7 de febrero; STC 6/1981, de 16 de marzo.

${ }^{24}$ Vide DE PALMA DEL TESO, A. "El contrato asistencial de Derecho administrativo. Los servicios sociales de atención a la tercera edad en Cataluña", Revista jurídica de Cataluña, 3, (2000), p. 45.

${ }^{25}$ Sobre el valor jurídico de estos principios rectores, resulta incuestionable el valor normativo de los preceptos constitucionales, superada la concepción de meras declaraciones programáticas, $\mathrm{Vi}^{-}$ de STG 19/1982, de 5 de mayo. En este ámbito, destaco las siguientes normas: Real Decreto Legislativo 1/2013, de 29 de noviembre, por el que se aprueba el Texto Refundido de la Ley General de Derechos de las Personas con Discapacidad y su Inclusión Social y la Ley 39/2006, de 14 de diciembre, de Promoción de la Autonomía Personal y Atención a personas en situación de Dependencia.

26 Vide ALEMÁN BRACHO, C. El sistema público de de servicios sociales, Impredisur, Granada, 1991, p. 206; LÓPEZ MENUDO, F. "Los derechos sociales en los Estatutos de Autonomía", Revista andaluza de Administración Pública, 73, (2009), pp. 97-106.

27 Vide: Ley 1/1999, de 31 de marzo, de Atención a las Personas con Discapacidad de Andalucía; Ley 11/2003, de 10 de abril, de la Generalitat sobre el Estatuto de las Personas con Discapacidad. 
el ámbito de las CCAA, a través de las leyes de acción social ${ }^{28}$. No obstante, la publicación de la Ley 27/2013, de 27 de diciembre, de racionalización y sostenibilidad de la Administración local (en adelante, LRSAL) ha venido a modificar notablemente este régimen competencial que se contenía en la Ley 7/1985, de 2 de abril, Reguladora de las Bases de Régimen Local, por el que la competencia propia que se regulaba sobre «servicios sociales y de promoción y reinserción social» ha pasado a atribuírsele íntegramente su titularidad a las CGAA, fijando como fecha límite desde 31 de diciembre de 2015 (DT segunda). En el ámbito social, la LRSAL atribuye como única competencia propia a las entidades locales la «evaluación e información de situaciones de necesidad social, y la atención inmediata a personas en situación o riesgo de exclusión social» (art. 8.2 LRSAL). Es por este motivo, por lo que cobra una especial importancia la labor desarrollada en el ámbito de los servicios sociales comunitarios, que en virtud de las competencias delegadas ${ }^{29}$ por las leyes de acción social, son las Entidades locales las responsables de su gestión ${ }^{30}$. En estos casos, es donde destaca la labor fundamental de estos servicios sociales, pues se convierten en el punto de acceso más inmediato ${ }^{31}$ en la protección de personas con necesidades sociales, y la vía que los canaliza hacia los recursos sociales más adecuados.

\section{G. La acción social como fundamento de actuación administrativa}

La acción social es la denominación más reciente y, más ampliamente aceptada por parte de la doctrina, para hacer referencia al ámbito de actuación pública y privada respecto de aquellas situaciones que necesitan una intervención específica. Comprende todas aquellas actuaciones desarrolladas por distintos actores sociales, que a través de diferentes formas de gestión pública y privada, tienden a la cobertura de las necesidades sociales individuales, así como aquellas otras que persiguen mejorar la calidad de vida de los ciudadanos logrando salvar desigualdades sociales y contribuyendo al bienestar social de toda la población ${ }^{32}$.

${ }^{28}$ Vide LÓPEZ FERNÁNDEZ, F.J. "Los gobiernos locales ante la exclusión social. Análisis del caso andaluz", El Consultor de los Ayuntamientos y de los Juzgados, 21, (2014), pp. 2267-2268.

${ }^{29}$ Vide CASTILLO BLANCO, F., y BARRANCO VELA, R. Competencias locales en materia de servicios sociales. Marco jurídico competencial en la actividad prestacional, CEMCI, Granada, 1994, pp. 133-134.

30 Vide LÓPEZ FERNÁNDEZ, F.J. "El papel de las entidades locales en el ámbito de la acción social en España”, Revista del Instituto de Ciencias furídicas de Puebla, 32, (2013), pp. 76-82.

31 Vide: Ley 13/2008, de 3 de diciembre, de Servicios Sociales de Galicia, art. 6.2; Ley 13/2010, de 20 de diciembre, de Servicios Sociales de Castilla y León, art. 7.j).

32 Vide LÓPEZ FERNÁNDEZ, F.J., Acción social en España (centros, servicios y establecimientos de servicios sociales), ACCI, Madrid, 2014, p. 34. 
En cuanto a su naturaleza jurídica, la acción social trasciende de la mera actividad administrativa de servicio público. Siguiendo a BELTRÁN AGUIRRE ${ }^{33}$, la acción social pública abarca otras actuaciones públicas o de intervención administrativa, como es el caso de actividades de fomento, que se manifiesta a través de subvenciones públicas, y actividades limitadoras, a través de autorizaciones administrativas, actuaciones inspectoras, o sancionadoras, entre otras.

Las Administraciones públicas autonómicas han configurado un sistema público de servicios sociales, compuesto por el conjunto de recursos, equipamientos y prestaciones de titularidad pública ${ }^{34}$ y privados, si estos últimos están previamente acreditados. Se trata de un auténtico sistema jurídico ${ }^{35}$, cuyos fines son la prevención ${ }^{36}$, es decir, la anticipación a los problemas de la sociedad, la promoción, que implica el diseño de políticas públicas a través de diferentes instrumentos como planes y programas $^{37}$, la asistencia, que implica una atención inmediata para erradicar la necesidad social de forma inminente y, la rehabilitación, caracterizada por los principios de normalización e integración con objeto de conseguir la autonomía plena ${ }^{38}$.

Estos fines se complementan con los objetivos que persigue la acción social y que justifican la intervención administrativa en este ámbito. En primer lugar, hay que entender a la acción social como una actividad prestacional ${ }^{39}$, que es aquélla en la que existiendo una necesidad pública y atendiendo al interés general, la Administración pública interviene proporcionando bienes y servicios a los ciudadanos ${ }^{40}$. En este sentido, cobra especial importancia los mecanismos de tutela que permite posibilitar la igualdad de oportunidades a aquellos que pueden verse en un estado de desventaja

${ }^{33}$ Vide BELTRÁN AGUIRRE, J.L. (1992): 70-71.

34 Vide Ley del Principado de Asturias 1/2003, de 24 de febrero, de Servicios Sociales, art. 2.

35 Vide ALONSO SECO, J.M., y GONZALO GONZÁLEZ, B. (2000): 186-192.

36 Vide MARTÍNEZ ROMÁN, M.A., y GUILLÉN SÁDABA, E. "La reorientación de los servicios sociales en los 80", en GARCÍA VILLALUENGA, L., (Coord.), El Derecho y los servicios sociales, Comares, Granada, 1997, p. 25: «Es más rentable, social y económicamente, prevenir los problemas sociales que tener que crear recursos sociales para remediar y paliar las consecuencias de no haber intervenido precozmente».

37 Vide: Ley del Principado de Asturias 1/2003, de 24 de febrero, de Servicios Sociales, art. 3.b); Ley Foral 15/2006, de 14 de diciembre, de Servicios Sociales de Navarra, art. 1.

38 Vide CASADO, D. Introducción a los Servicios Sociales, Acebo, Madrid, 1991, pp. 83-86.

39 Vide: CASTILLO BLANCO, F., y BARRANCO VELA, R. (1994): 49; Ley 4/2009, de 11 de junio, Servicios Sociales de Islas Baleares, art. 20.1; Ley 11/2003, de 27 de marzo, de Servicios Sociales de la Comunidad de Madrid, art. 14.

40 Vide: PARADA VÁZQUEZ, R. Derecho Administrativo I. Parte General, Marcial Pons, Madrid, 2007, p. 377; GARRIDO FALLA, F., y Otros, Tratado de Derecho Administrativo. Parte General: conclusión, Tecnos, Madrid, 2006, p. 401. 
(incapacidad, enfermedad, soledad, etc.) que la Administración debe corregir. En segundo lugar, vemos a la acción social como un instrumento de planificación, ordenación y cooperación administrativa. Estas actuaciones son necesarias por el número tan variado de necesidades sociales (destinatarios), recursos sociales, actores intervinientes, fórmulas de gestión ${ }^{41}$, etc., cuyo principal objetivo es evitar posibles desequilibrios territoriales. Por este motivo, es frecuente el establecimiento de una planificación general ${ }^{42}$, la aprobación de un catálogo ${ }^{43}$ de recursos sociales (se configuran como derechos subjetivos ${ }^{44}$ ), y la organización de los mismos en base a dos criterios, uno funcional y otro territorial ${ }^{45}$. En último lugar, ha de entenderse la acción social como un instrumento de limitación de los derechos particulares en la gestión de los recursos sociales ${ }^{46}$. Esta limitación efectuada por el poder público en garantía del interés general, se concretará a través de la exigencia de una serie de autorizaciones administrativas o comunicaciones previas, la inscripción en un registro de naturaleza pública, la acreditación administrativa, la supervisión, control e inspección de los centros, servicios y establecimientos de servicios sociales, así como el sometimiento de la actuación a la potestad sancionadora de la Administración pública en caso de incumplimiento $^{47}$.

\section{Las personas adultas como personas incapaces}

Los poderes públicos tienen la obligación de proteger a todas aquellas personas o colectivos desfavorecidos socialmente. Uno de estos colectivos lo constituyen las personas adultas. En el ámbito de las CCAA, la utilización del término «adulto» se ha

41 Vide VILLAR ROJAS, F.J. "Formas de gestión de los servicios sociales. En particular, la vinculación de gestores privados al sistema público mediante conciertos y convenios", Documentación Administrativa, 271-272, (2005), p. 391.

42 Vide: ALEMÁN BRACHO, C. "La planificación en las leyes de servicios sociales", Revista de la Facultad de Derecho de la Universidad de Granada, 14, (1987), p. 9; Ley 5/2009, de 30 de junio, de Servicios Sociales de Aragón, art. 39.1.

43 Vide: Ley 12/2007, de 11 de octubre, de Servicios Sociales de Cataluña, art. 24.2; Ley 5/2009, de 30 de junio, de Servicios Sociales de Aragón, art. 32.

44 Vide LÓPEZ MENUDO, F. (2009): 92.

45 Vide LÓPEZ FERNÁNDEZ, F.J. (2014): 90-107.

46 Vide PARADA VÁZQUEZ, R. (2007): 345.

47 Vide: FERNÁNDEZ RAMOS, S. "La ordenación general de los servicios sociales en Andalucía: situación actual y prospectiva", en FERNÁNDEZ RAMOS, S., y PÉREZ MONGUIÓ, J.M., (Coord.), El Derecho de los Servicios Sociales en Andalucía, Instituto Andaluz de Administración Pública, Sevilla, 2012, pp. 165-187; VILLAR ROJAS, F.J. "Iniciativa privada y prestación de servicios sociales. Las redes o sistemas públicos de servicios sociales", en EZQUERRA HUERVA, A., (Coord.), El marco jurídico de los servicios sociales en España, Atelier, Barcelona, 2012, pp. 87-121; LÓPEZ FERNÁNDEZ, F.J. (2014): 270-317. 
caracterizado por su contraposición con otros términos con mayor tradición y repercusión a efectos jurídicos, como instituciones tan consagradas como «menores»o «mayores». El hecho de que hablemos de personas adultas, nos hace indicar que el ámbito subjetivo que la Administración pública va a proteger es el de personas mayores de dieciocho años ${ }^{48}$, por tanto, excluye a los menores de edad, que contemplan otro ámbito específico de protección ${ }^{49}$. De igual modo, la no utilización del término «mayor» corresponde a la identificación de éste con un ámbito ya propio dentro de la acción social, comprendiendo a las personas mayores de sesenta y cinco años, para los que los poderes públicos también ya han creado un sistema público de protección a través de diferentes programas y recursos sociales ${ }^{50}$. En consecuencia, los poderes públicos han optado por utilizar un término nuevo como es el de "persona adulta» para referirse a todas aquellas personas que siendo mayores de dieciocho años y sin límite de edad, precisan, por las circunstancias que ahora veremos, de una especial protección.

A este elemento subjetivo, se suman otros elementos que terminan por configurar este término. En concreto, como elemento objetivo ha de precisarse que las personas adultas ostentan una capacidad legal limitada como consecuencia de las causas establecidas en el art. 200 Cc., esto es, padecer «enfermedades o deficiencias persistentes de carácter físico o psíquico, que impidan a la persona gobernarse por sí misma». De este precepto se desprenden dos características esenciales en estos casos de incapacidad, y que deben acontecer necesariamente de forma conjunta ${ }^{51}$ : por un lado, la que se refiere a las enfermedades o deficiencias persistentes de carácter físico o psíquico, que según reiterada jurisprudencia interpreta la necesidad de que las mismas sean persistentes o permanentes e irreversibles y, en consecuencia, no remitan ni de forma espontánea ni terapéutica ${ }^{52}$. Por otro lado, la que se refiere a la posibilidad de que la persona pueda gobernarse por sí misma, y que constituye un requisito esencial

48 Vide Ley 11/2003, de 27 de marzo, de Servicios Sociales de la Comunidad de Madrid, art. 23.1 .

${ }^{49}$ A modo de ejemplo y de ámbito nacional, Vide: Ley Orgánica 1/1996, de 15 de enero, de protección jurídica del menor y de modificación parcial del Código Civil y de la Ley de Enjuiciamiento Civil; Ley Orgánica 5/2000, de 12 de enero, reguladora de la responsabilidad penal de los menores; Ley 40/2003, de 18 de noviembre, de Protección a las Familias Numerosas; Instrumento de ratificación de 30 de noviembre de 1990 de la Convención de las Naciones Unidas sobre los Derechos del Niño y la Niña, etc.

${ }^{50}$ A modo de ejemplo y de ámbito autonómico, Vide: Ley 6/1999, de 7 de julio, de Atención y Protección a las Personas Mayores en Andalucía; Ley 5/2003, de 3 de abril, de Atención y Protección a las Personas Mayores de Castilla y León; etc.

${ }^{51}$ Vide: STS 28/07/1998.

52 Vide STS 29/04/2009. 
para acordar la incapacidad del sujeto. El Tribunal Supremo define el autogobierno como «la idoneidad de la persona para administrar sus intereses, intereses que comprenden no sólo los materiales, sino también los morales y, por ende, la guarda de la propia persona» ${ }^{53}$. Se produce, por tanto, una importante limitación funcional, que ha de ser total y permanente ${ }^{54}$, que conlleva la ausencia de una reflexión en el actuar 55 .

Otro elemento a tener en cuenta, es el conectivo que permite relacionar los anteriores elementos subjetivo y objetivo, y que en estos casos, se manifiesta en la necesidad de que la incapacidad de las personas adultas se declare en virtud de sentencia judicial, tal y como se desprende del art. 199 Cc. El Tribunal Supremo, también nos define la incapacitación, como «la decisión judicial de carecer de aptitud una persona para autogobernarse respecto a su persona y patrimonio» ${ }^{56}$, por tanto, vemos la necesidad de que sea la autoridad judicial quien declare la incapacidad atendiendo a las causas que se han descrito anteriormente, valorando la extensión y límites de la misma ${ }^{57}$, con objeto de conseguir las máximas garantías e instrumentos necesarios en la protección de la persona. Con este fin, el citado Tribunal señala, respecto a la función de los juzgadores:

«La función judicial les adentra en el proceso no sólo como árbitros y directores del mismo, sino también como activos integrantes, que, sin ser propias partes procesales, sí son interesados en la aportación de todo el material preciso probatorio, desde los exámenes directos del presunto incapaz, tanto por el Juez de la instancia, como por el Tribunal, si éste es el que declara la incapacidad, en una actuación que ni puede calificarse de reconocimiento judicial $[\ldots]$, ni de inspección personal [...] y menos de mezcla de ambos [...], sino que se trata de una prueba directa, legal, autónoma y obligada $[\ldots]$, componen el material probatorio suficiente para dictar la decisión judicial que, en el ámbito civil, se presenta como una de las más trascendentales, ya que afecta a la libertad propia de los seres humanos, por lo que estas cuestio-

53 Vide STS 14/07/2004. Sobre este aspecto, la sentencia alude a las tres dimensiones del autogobierno desde el punto de vista médico: la patrimonial (autonomía e independencia en la actividad socioeconómica), la adaptativa e interpersonal (entendiendo por tal la capacidad de afrontar los problemas de la vida diaria en la forma y manera que sería de esperar para su edad y contexto sociocultural) y la personal (en el sentido de desplazarse eficazmente dentro de su entorno, mantener una existencia independiente en relación con las necesidades físicas más inmediatas, incluyendo alimentación, higiene y autocuidado).

${ }^{54}$ Vide: STS 29/04/2009; STS 31/10/1994.

55 Vide Stc. de la Audiencia Provincial de Jaén de 13/02/2008.

56 Vide: STS14/07/2004; STS 31/12/1991; STS 31/10/1994; STS 16/09/1999.

57 Vide: Ley 1/2000, de 7 de enero, de Enjuiciamiento Civil, art. 760; STS 14/07/2004; STS 16/09/1999. 
nes no deben permanecer lejanas a la sensibilidad y carga humana de los juzgadores a los que corresponde emitir la respuesta-Sentencia adecuada» ${ }^{58}$.

Finalmente, como elemento teleológico, ha de precisarse que las personas adultas son sujetos a los que les es imposible participar en los distintos aspectos de la vida, ya sean personales (vestir, pasear, etc.) familiares (compra, limpieza, etc.) sociales (visitas, relaciones, etc.) e incluso patrimoniales (control de cuentas, recibos, etc.) ${ }^{59}$, por tanto, existe una manifiesta incapacidad para el desarrollo o ejercicio de tareas físicas o intelectuales que se producen habitualmente, en el día a día, necesitando la ayuda y supervisión de otra persona. La jurisprudencia del Tribunal Supremo entiende que la carencia o limitación de tales funciones se encuentran estrechamente vinculadas con la propia dignidad de la persona ${ }^{60}$, por tanto, es la persona misma la que centra la atención de los juzgadores en su función de declarar o privar la capacidad jurídica de obrar ${ }^{61}$. Esto justifica no sólo la necesidad de tal declaración por la autoridad judicial, sino la correspondiente protección de la Administración pública, a través de la dotación de los recursos sociales necesarios, a fin de garantizar su integración y normalización, y evitar situaciones específicas de discriminación y desigualdad.

\section{LA NEGESIDAD DE INTEGRAR LA INGAPACIDAD EN OTRAS INSTITUCIONES JURÍDICO-ADMINISTRATIVAS}

Es común al ámbito social de las CCAA la carencia de referencias específicas sobre la protección de personas adultas. Tal y como había adelantado en anteriores epígrafes, este colectivo carece de la relevancia de otras instituciones consagradas que habitualmente contemplan las normas reguladoras de acción social. Si acudimos a las leyes de acción social, lo más próximo y como excepción, lo vemos regulado en la Ley 11/2003, de 27 de marzo, de Servicios Sociales de la Comunidad Autónoma de Madrid, que distingue entre tres sectores de actuación: menores, adultos y mayores. Respecto a los adultos, determina la Ley que lo constituyen aquellas personas que sean mayores de edad y no hayan cumplido los 65 años (art. 22.1), concretando entre

\footnotetext{
58 Vide STS 31/12/1991.

59 Vide STS 29/04/2009.

${ }^{60}$ Vide STS 16/09/1999.
}

${ }^{61}$ Vide STS 31/12/1991. Define la capacidad jurídica de obrar como «aptitud innata para ser sujeto de derechos y obligaciones, determinada por el nacimiento (art. 29 Cc.) e inherente a la condición de ciudadanos que desarrollan su actividad vital en una comunidad organizada, por ser consustancial a su dignidad y proyectar el ejercicio y libre desarrollo de cada personalidad, conforme al art. $10 \mathrm{CE} »$. 
sus líneas fundamentales de actuación «la protección jurídica de las personas adultas en situación de desamparo» [(art. 22.3.d)]. Precisamente en cumplimiento de tal precepto, publicó esta Comunidad Autónoma la Ley 4/1995, de 21 de marzo, de creación de la Agencia Madrileña para la Tutela de Adultos, con el fin de proteger mediante diferentes instituciones civiles las personas con capacidad legal limitada (art. 3). Sin embargo, no hace referencia a las medidas concretas de protección social, esto es, recursos sociales específicos que mejor puedan adaptarse a las necesidades de estas personas ${ }^{62}$.

A través de este ejemplo, vemos la importante labor de la Administración pública en la protección de las personas adultas, que es la que se ejerce mediante las distintas instituciones civiles (tutela, curatela, etc.) siempre que la misma haya sido declarada mediante sentencia judicial. No obstante, la trascendental función de la Administración pública, no acaba precisamente con esta actuación, pues también ha proveer a dichas personas de los recursos sociales necesarios para garantizar su integración y normalización en la sociedad. Es en el desempeño de esta doble función donde las personas adultas escapan de la atención específica de los poderes públicos y han de ser incluidas entre otras categorías jurídico-administrativas a fin de convertirse en titulares de derechos y obligaciones en el ámbito social. En concreto me refiero tanto a las personas con discapacidad como a las personas en situación de dependencia, que veremos a continuación.

\section{Incapacidad y discapacidad}

Una vez que hemos concretado el concepto y los caracteres que son propios de las personas adultas y, en particular, su elemento esencial basado en la incapacidad, toca ahora analizar su relación con otros conceptos propios de la acción social como en este caso es la discapacidad.

El Real Decreto Legislativo 1/2013, de 29 de noviembre, por el que se aprueba el Texto Refundido de la Ley General de Derechos de las personas con discapacidad y de su inclusión social, define a las personas con discapacidad ${ }^{63}$ como «aquellas que

${ }^{62}$ En sentido parecido, Vide Ley 12/2008, de 5 de diciembre, de Servicios Sociales del País Vasco, en el que a través del catálogo de recursos sociales, se contempla el servicio de tutela para personas adultas incapacitadas.

63 Vide DE LORENZO GARGÍA, R., y PALACIOS, A. "Los grandes hitos de la protección jurídica de las personas con discapacidad en los albores del siglo XXI", Documentación Administrativa, 271-272, (2005), p. 296 
presentan deficiencias ${ }^{64}$ físicas, mentales, intelectuales o sensoriales, previsiblemente permanentes que, al interactuar con diversas barreras, puedan impedir su participación plena y efectiva en la sociedad, en igualdad de condiciones con los demás» (art. 4.1). A todos los efectos, serán consideradas personas con discapacidad aquéllas a quienes se les haya reconocido un grado de discapacidad igual o superior al 33\% (art. $4.2)$.

Establecida esta definición nos cabe preguntar si la incapacidad y la discapacidad es lo mismo, pues coinciden en ciertos elementos, como las deficiencias que han de presentarse (físicas o psíquicas), su presencia de carácter permanente, previsibles limitaciones sociales, etc., aunque difieren en su reconocimiento pues las primeras está atribuido a las autoridades judiciales y las segundas a la propia Administración pública. El hecho de que la incapacidad y la discapacidad puedan provenir de similares enfermedades o deficiencias, nos obliga a centrarnos como elemento clave en el establecido en el propio Código Civil, cuando determina en relación a las causas de incapacitación la posibilidad de que el sujeto pueda gobernarse por sí mismo (art. 200).

La discapacidad ofrece la posibilidad de ser modulada en virtud de la valoración que los órganos competentes realizan atendiendo al baremo publicado ${ }^{65}$, y que se especifica a través del reconocimiento del grado de discapacidad, que como hemos indicado, puede provenir por enfermedades o deficiencias de carácter físico o psíquico. Hemos de considerar, por ejemplo, que un grado de discapacidad de carácter físico y reconocido en un porcentaje inferior $(33 \%)$ no tiene por qué influir en la capacidad volitiva y cognitiva del sujeto. Pero incluso, un grado de discapacidad psíquica reconocido según el baremo en un grado inferior, tampoco tiene por qué derivar en una presunta incapacidad. En conclusión, ha de precisarse que no toda discapacidad conlleva necesariamente la imposibilidad de autogobierno y, en consecuencia, no toda persona discapacitada tiene por qué estar o ser incapacitada judicialmente. En definitiva, no son términos equiparables.

${ }^{64}$ Vide PÉREZ GÁLVEZ, J.F. (2006): 462-463. Se distinguen los siguientes términos: «a) Deficiencia: dentro de la experiencia de la salud, una deficiencia es toda pérdida o anormalidad de una estructura o función psicológica, fisiológica o anatómica; b) Discapacidad: dentro de la experiencia de la salud, una discapacidad es toda restricción o ausencia (debido a una deficiencia) de la capacidad de realizar una actividad en la forma o dentro del margen que se considera normal para un ser humano; c) Minusvalía: dentro de la experiencia de la salud, una minusvalía es una situación desventajosa para un individuo determinado, consecuencia de una deficiencia o de una discapacidad que limita o impide el desempeño de un rol que es normal en su caso (en función de la edad, sexo y factores sociales y culturales)».

65 Vide Real Decreto 1971/1999, de 23 de diciembre, de procedimiento para el reconocimiento, declaración y calificación del grado de discapacidad, Anexo I y II. 
Sin embargo, nos surge la pregunta establecida en sentido contrario. ¿ Toda persona incapacitada es o puede ser una persona con discapacidad?. Según el baremo regulado por el Real Decreto 1971/1999, de 23 de diciembre, de procedimiento para el reconocimiento, declaración y calificación del grado de discapacidad, y teniendo en cuenta la importancia que cobra en su valoración el aspecto psíquico para determinar la posibilidad o no de autogobierno, su análisis se centrará es aspectos relacionados con posibles enfermedades de carácter mental ${ }^{66}$. En virtud de estos aspectos y teniendo en cuenta, que la persona incapacitada posee una capacidad legal limitada, lo suficientemente importante como para que la autoridad judicial haya declarado su incapacidad legal, nos hace concluir no sólo en el sentido afirmativo de que probablemente se le reconozca el grado de discapacidad, sino que además lo sea en un porcentaje alto o muy alto (al menos del $65 \%$ ).

\section{Incapacidad y dependencia}

Otra de las instituciones con las que habrá que delimitar el alcance que en el ámbito social ostenta la incapacidad es con la dependencia. La Unión Europea define la dependencia como «el estado en el que se encuentran las personas que por razones ligadas a la falta o la pérdida de autonomía física, psíquica o intelectual tienen necesidad de asistencia y/o ayudas importantes a fin de realizar los actos corrientes de la vida diaria» ${ }^{67}$. Se contemplan por tanto, tres factores que concurren en esta definición y que también han sido establecidos por la Ley 39/2006, de 14 de diciembre, de Promoción de la Autonomía Personal y Atención a las personas en situación de dependencia (art. 2.2): la existencia de alguna limitación física o mental que merma las capacidades de la persona, la imposibilidad de realizar actos corrientes de la vida diaria y la necesidad de cuidados por parte de otras personas.

Estos caracteres se aproximan a los establecidos para la incapacidad, si bien, ha de tenerse en cuenta las siguientes consideraciones. En la definición de dependencia el elemento clave que determina su naturaleza es la necesidad de ser ayudado, esto es, la concurrencia de otra persona para la realización de las actividades básicas de la vida diaria. Sin embargo, en la incapacitación, el elemento delimitador sigue estando en la capacidad intelectual del sujeto para gobernarse a sí mismo. Esto implica que la necesidad de ser ayudado por otra persona, aunque la misma fue-

66 Vide Real Decreto 1971/1999, de 23 de diciembre, de procedimiento para el reconocimiento, declaración y calificación del grado de discapacidad, Anexo I. Se tiene en cuenta en su valoración: a) Disminución del individuo para llevar a cabo una vida autónoma; b) Disminución de la capacidad laboral; c) Ajuste a la sintomatología psicopatológica universalmente aceptada.

67 Vide Consejo de Europa. Recomendación No. R (98) 9 del Comité de Ministros a los Estados Miembros relativa a la dependencia. 
ra muy intensa, no es motivo suficiente para ser considerado legalmente incapaz, pues puede regir con plena capacidad su autogobierno. En estos casos lo verdaderamente importante es la existencia de determinadas enfermedades o deficiencias mentales que terminen por anular la capacidad de decisión del sujeto, ya que el concurso o no de una tercera persona es una consecuencia de está limitación, que si bien es elemento delimitador de la dependencia, no lo es respecto de la incapa$\operatorname{cidad}^{68}$. Lo que significa, en términos generales, que dependencia e incapacidad no son términos equiparables.

Ahora bien, igual que en el caso anterior nos hacemos la pregunta en sentido contrario. ¿'Toda persona incapacitada judicialmente es persona dependiente? En estos casos, habrá que atender a la valoración practicada por los Órganos de Valoración de las $\mathrm{CCAA}^{69}$, en virtud del baremo publicado a través del Real Decreto 174/2011, de 11 de febrero. En estos casos, se va a atender a la necesidad de atención de otras personas o ayudas importantes para realizar las actividades básicas de la vida diaria. La propia Ley 39/2006, de 14 de diciembre, determina para los casos de personas con discapacidad intelectual o enfermedad mental, el hecho de que precisen «de otros apoyos para su autonomía personal» ${ }^{70}$, lo que en definitiva implica una cierta capacidad de toma de decisiones personales así como de desarrollo de las actividades básicas de la vida diaria ${ }^{71}$, que en estos casos no la tienen. Por este motivo, puedo afirmar que las personas incapacitadas legalmente muy probablemente sean valoradas como personas dependientes.

${ }^{68}$ Vide QUEREJETA GONZÁLEZ, M. Discapacidad/Dependencia: unificación de criterios de valoración y clasificación, Ministerio de Trabajo y Asuntos Sociales, Madrid, 2004, pp. 39-40.

${ }^{69}$ A modo de ejemplo, Vide Decreto 168/2007, de 12 de junio, por el que se regula el procedimiento para el reconocimiento de la situación de dependencia y del derecho a las prestaciones del Sistema para la Autonomía y Atención a la Dependencia, así como los órganos competentes para su valoración en la Comunidad Autónoma de Andalucía. Vide: PÉREZ CASTILLO, R., y OLMEDO AREAL, J.M. El procedimiento para el Reconocimiento de la situación de Dependencia: perspectivas de Desarrollo y de Futuro en el Marco del Estado de Bienestar Social en la Comunidad Autónoma Andaluza, Instituto Andaluz de Administración Pública, Sevilla, 2009, pp. 57-58; TORRES LÓPEZ, M.A. "La gestión de la política de dependencia en la Comunidad Autónoma de Andalucía. La Agencia andaluza para la atención de la dependencia", Revista andaluza de Administración Pública, 77, (2010), pp. 322-323.

${ }^{70}$ Vide Ley 39/2006, de 14 de diciembre, de Promoción de la Autonomía Personal y Atención a las personas en situación de dependencia, art. 2.2 (inciso final).

${ }^{71}$ Vide Ley 39/2006, de 14 de diciembre, de Promoción de la Autonomía Personal y Atención a las personas en situación de dependencia, art. 2.1. 


\section{Las personas adultas como titulares de derechos y obli- gaciones en el ámbito social}

Las personas adultas como sujetos a los que les habrá sido reconocido un grado de discapacidad y/o de dependencia, acceden desde ese momento al sistema público de servicios sociales y, en consecuencia, ostentan todos los derechos y obligaciones que se configuran en el ámbito social para estos sectores. Dicho reconocimiento no opera de forma automática, esto es, habrá de solicitarse por quienes han asumido su protección civil (tutela, etc.). Por este motivo, habrá que recurrir a la Administración pública a fin de proveerlos de los recursos sociales oportunos, que en función de sus circunstancias mejor se adapten a sus necesidades.

Las leyes de servicios sociales más recientes ${ }^{72}$ contienen un exhaustivo catálogo de derechos y obligaciones que estructuran en base a dos criterios: en primer lugar, derechos y obligaciones generales de acceso $^{73}$ al sistema público de servicios sociales y, por tanto, extensivo respecto a cualquier ciudadano. Estos derechos y obligaciones se caracterizan porque no precisan de una actuación previa por parte de la Administración pública, esto es, no necesitan de un reconocimiento expreso que delimite su contenido y efectos, por tanto, se ostenta por el simple hecho de ser persona humana $^{74}$. Entre estos derechos, es muy innovador, lo contemplado por algunas CCAA, que literalmente cito:

«A dar instrucciones previas para situaciones futuras de incapacidad respecto a asistencia o cuidados que se le puedan procurar y derecho a la autotutela, entendiéndose por tal la posibilidad de nombrar anticipadamente a la persona que le representará y ejercerá la tutela sobre su persona y bienes en caso de pérdida de su capacidad de autogobierno, en los términos previstos en el Código Civil» ${ }^{75}$.

72 Vide: EZQUERRA HUERVA, A. "El estatuto jurídico de los usuarios de centros y establecimientos de servicios sociales", en EZQUERRA HUERVA, A. Ciudadanos y prestaciones sociales residenciales, Iustel, Madrid, 2011, p. 59; Ley 14/2010, de 16 de diciembre, de Servicios Sociales de Castilla La Mancha, arts. 10 y 11; Ley 16/2010, de 20 de diciembre, de Servicios Sociales de Castilla y León, arts. 11 y 12.

${ }^{73}$ Vide: TORNOS MAS, J. "Efectividad de los derechos y exigibilidad de los servicios sociales", Documentación Administrativa, 271-272, (2005), p. 381; ALONSO SECO, J.M., y GONZALO GONZÁLEZ, B. (2000): 238-249.

${ }^{74}$ Existen otros derechos generales, que considero que no serían necesarios su formulación, ya que se limitan a reproducir derechos que no sólo se consideran inherentes a la persona humana sino que existen vías alternativas para su defensa y respeto en caso de vulneración, como el ser tratados con respeto a la dignidad que tienen como personas o a que se le respeten los derechos y libertades fundamentales, entre otros.

75 Vide: Ley 12/2008, de 5 de diciembre, de Servicios Sociales del País Vasco, art. 9.d); Ley 13/2008, de 3 de diciembre, de Servicios Sociales de Galicia, art. 6.1). 
En segundo lugar, se regulan un conjunto de derechos y obligaciones específicos, es decir, exclusivamente para aquellas personas que ya han accedido al sistema público de servicios sociales y, por tanto, extensivo sólo a los usuarios del mismo. En estos casos, la posición jurídica que adoptan los usuarios se fundamenta en la resolución o acto administrativo que dicte la Administración pública por el que se reconoce la prestación social correspondiente y, en cierto modo, vincula a las partes pues surge una especial relación jurídica entre la Administración pública y el interesado convirtiéndose ambos en sujetos de derechos y obligaciones recíprocos ${ }^{76}$. Su rasgo principal es la protección de los usuarios que ya de por sí presentan una especial vulnerabilidad, al tiempo que responsabilizarlos en el buen funcionamiento de los recursos. Algunos ejemplos sobre esta cuestión los podemos ver, respecto al servicio de atención residencial, en la obligación de respetar las normas de régimen interior, abonar los gastos que genera la prestación, el derecho a recibir visitas, etc.

Finalmente, debe destacarse en este apartado, la importante transformación que durante estos últimos años se está produciendo en la naturaleza jurídica de ciertas prestaciones sociales, que convierten a las personas adultas en titulares de auténticos derechos subjetivos. Ha de precisarse que no todos los recursos sociales contenidos en las leyes de acción social lo son, habrá que acudir, por tanto, a la cartera o catálogo de recursos sociales establecida en dichas leyes para ver cuáles tienen dicha naturaleza, que atendiendo al ámbito autonómico en el que nos encontremos, aparecerán calificados como «esenciales», «básicos», «garantizados» o «fundamentales» ${ }^{77}$. Su importancia radica en la posibilidad añadida de poder exigir su cumplimiento mediante las garantías procesales correspondientes, lo que permite «la existencia de un mecanismo de tutela judicial efectivo mediante el que poder exigir el derecho a una prestación que la Ley reconoce como derecho subjetivo» ${ }^{78}$.

76 Vide: GONZÁLEZ NAVARRO, F. Derecho Administrativo Español, EUNSA, Pamplona, 1994, p. 34; ALONSO SECO, J.M. "El status jurídico-administrativo del interno en centros de la red pública asistencial: derechos y obligaciones", Documentación Administrativa, 271-272, (2005), p. 417.

${ }^{77}$ A modo de ejemplo, Vide Ley 5/2009, de 30 de junio, de Servicios Sociales de Aragón, art. 1.2; Ley Foral 15/2006, de 14 de diciembre, de Servicios Sociales de Navarra, art. 10.2; entre otras.

${ }^{78}$ Vide TORNOS MAS, J. (2005): p. 386. Este autor destaca la importante labor que adquiere en estos casos la figura del Defensor del Pueblo y los Defensores del Pueblo autonómicos y locales. Vide SALAMERO TEIXIDÓ, L. "Los mecanismos de control como garantía de los derechos de los usuarios de centros y establecimientos de servicios sociales", en EZQUERRA HUERVA, A. (2011): 197-207. Esta autora junto a la figura del Defensor del Pueblo, destaca también la importante labor en la protección de los derechos de los particulares que ha de realizar el Ministerio Fiscal. Vide: Ley 14/2010, de 16 de diciembre, de Servicios Sociales de Castilla La Mancha, art. 1; Ley 14/2010, de 16 de diciembre, de Servicios Sociales de Castilla La Mancha, art. 37; Ley 39/2006, de 14 de diciembre, de Promoción de la Autonomía Personal y Atención a las personas en situación de dependencia, art. 4.2.j). 


\section{III. ¿QUÉ ENTIDADES PARTICIPAN EN LA TUTELA DE PER- SONAS ADULTAS?}

Una importante novedad en la tutela de personas incapacitadas lo supuso la publicación de la Ley 13/1983, de 24 de octubre, de Reforma del Código Civil. A través de esta norma se modificó el art. 242 Cc., introduciendo la posibilidad de que, junto a las personas físicas, también las jurídicas (tanto públicas como privadas) pudieran ser tutores tanto de menores como de incapacitados.

Entre las distintas entidades tutelares que intervienen se va a desarrollar una importante labor por la Administración pública, ya que su función no acaba precisamente con la tutela de personas adultas sino con la provisión de un sistema público de recursos sociales a fin de completar el sistema protector de estas personas incapacitadas. Junto a la Administración pública también van a participar un variado conjunto de entidades, que si bien, algunas centrarán su actuación en el ejercicio de la tutela propiamente dicha, concurrirán otras cuya finalidad sea la prestación de recursos sociales, como tendremos ocasión de ver más adelante.

\section{Administración pública}

La intervención de la Administración pública en este ámbito está justificada en virtud del art. 239 del Cc., que literalmente dispone:

«La entidad pública a la que, en el respectivo territorio, esté encomendada la tutela de los incapaces cuando ninguna de las personas recogidas en el artículo 234 sea nombrado tutor, asumirá por ministerio de la ley la tutela del incapaz o cuando éste se encuentre en situación de desamparo. Se considera como situación de desamparo la que se produce de hecho a causa del incumplimiento o del imposible o inadecuado ejercicio de los deberes que le incumben de conformidad a las leyes, cuando éstos queden privados de la necesaria asistencia moral o material» ${ }^{79}$.

De este precepto se deduce que la actuación de la Administración pública en el ejercicio de la tutela es de carácter subsidiario, y ello implica que esta actuación es elegida en defecto de persona física, y más en concreto, de las personas establecidas

${ }^{79}$ Este párrafo ha sido introducido por el número tres del art. 9 de la Ley 41/2003, de 18 de noviembre, de protección patrimonial de las personas con discapacidad y de modificación del Código Civil, de la Ley de Enjuiciamiento Civil y de la Normativa Tributaria con esta finalidad. 
por el propio $\mathrm{Cc}^{80}$. Por este motivo, en caso de no existir persona física que pueda asumir tal responsabilidad tutelar, o habiéndola el juez considera que no reúne las características idóneas exigidas o simplemente no quiere ejercerla, el propio CC., le otorga la posibilidad de que, en resolución motivada, pueda alterar el orden establecido en el citado Código o incluso prescindir de todas ellas, siempre que el beneficio de la persona incapacitada así lo exija ${ }^{81}$. Se protege en estos casos el interés más relevante, que es el del incapacitado de la protección tutelar, y no de los llamados a ejercerla si es que los hay ${ }^{82}$. Asimismo, también se le otorga la posibilidad de que designe «tutor a quien, por sus relaciones con el tutelado y en beneficio de éste, considere más idóneo» (art. 235).

De los preceptos anteriores se justifica la intervención de la Administración pública en la tutela de personas adultas. Si además la acompañamos del principio de responsabilidad pública que preside la actuación de la Administración pública en el ámbito social, no nos queda ninguna duda del compromiso que los poderes públicos asumen obligatoriamente en la protección de las personas incapacitadas judicialmente, para lo que necesariamente han de disponer de todos los recursos humanos, financieros y técnicos que les son posibles ${ }^{83}$.

En el ámbito de la Comunidad Autónoma de Andalucía, la Administración autonómica asume, a través de su Estatuto de Autonomía, competencia exclusiva en materia de acción social bajo la denominación «servicios sociales, voluntariado, menores y familias» ${ }^{84}$. De forma específica, dicha competencia incluye «las instituciones públicas de protección y tutela de personas necesitadas de protección especial, incluida la creación de centros de ayuda, reinserción y rehabilitación» [(art. 61.1.c)]. Vemos un claro ejemplo, en virtud del cual, es la Administración pública y, en este caso la autonómica, la primera llamada a ejercer la tutela de las personas incapacitadas judicialmente ${ }^{85}$, y ello sin perjuicio de la posibilidad de participación que tam-

${ }^{80}$ Vide Código Civil, art. 234. Esta norma señala que se preferirá para el nombramiento de tutor a las siguientes personas físicas: a) Al designado por el propio tutelado; b) Al cónyuge que conviva con el tutelado; c) A los padres; d) A la persona o personas designadas por éstos en sus disposiciones de última voluntad; e) $\mathrm{Al}$ descendiente, ascendiente o hermano que designe el juez.

81 Vide Código Civil, art. 234, inciso final.

82 Vide: STS 01/07/2004; STS 17/07/2012.

83 Vide Ley 12/2007, de 11 de octubre, de Servicios Sociales de Cataluña, art. 5.c).

84 Vide Ley Orgánica 2/2007, de 19 de marzo, de reforma del Estatuto de Autonomía para Andalucía, art. 61.

85 Vide Dirección General de Personas con Discapacidad, Protocolo de actuación de las entidades tutelares en Andalucía, 2012, p. 18. 
bién pueden tener las entidades locales, si en virtud de delegación ${ }^{86}$ así se les encomienda, previa aceptación del municipio interesado y acompañada de la correspondiente financiación ${ }^{87}$.

En cuanto al ejercicio de la tutela, la Administración pública podrá llevarla a cabo de diferentes modos. En primer lugar, puede ocurrir que la Administración pública decida ejercer dicha institución de forma directa ${ }^{88}$, esto es, a través de sus propios órganos administrativos. Esto implica que dicha labor sea desempeñada por parte de su propio personal atendiendo a la relación de puestos de trabajo y plantilla presupuestaria. Serán los empleados públicos ${ }^{89}$ (personal funcionario o laboral) a quienes se les asigne el objetivo de desarrollar las tareas propias de esta institución ${ }^{90}$.

En segundo lugar, cabe la posibilidad de que la Administración pública intervenga a través de determinadas personas jurídicas creadas por las mismas, en régimen de descentralización funcional ${ }^{91}$. A través de esta «Administración instrumental» ${ }^{92}$,

86 Vide MORENO MOLINA, A.M. "Las competencias de las entidades locales", en CASTILLO BLANCO, F., (Coord.), Modificaciones y panorama actual del régimen local español, Centro de Estudios Municipales y de Cooperación Internacional, Granada, 2000, p. 90.

87 Vide Ley 7/1985, de 2 de abril, reguladora de las Bases del Régimen Local, art. 27, tras su reforma por la Ley 27/2013, de 27 de diciembre, de racionalización y sostenibilidad de la Administración Local.

${ }^{88}$ Vide NIETO, A. "La organización de las Administraciones públicas para el servicio del bienestar”, en MUÑOZ MACHADO, S., GARCÍA DELGADO, J.L., y GONZÁLEZ SEARA, L. (2000): 560 .

${ }^{89}$ Vide Ley 7/2007, de 12 de abril, del Estatuto Básico del Empleado Público, art. 8. Sobre la importancia de la publicación de dicha Ley, Vide CASTILLO BLANCO, F. "El empleo público: distribución de competencias, regulación y clases de empleados", en CANO CAMPOS, T., (Coord.), Lecciones y materiales para el estudio del Derecho administrativo, Iustel, Madrid, Vol. 2, 2009, p. 501-509.

${ }^{90}$ Vide Decreto 71/1997, de 17 de junio, de la Comisión de Tutela de Castilla La Mancha, arts. 1 y 4. Esta Comisión es un órgano interdepartamental bajo la dependencia de la Consejería de Sanidad y Asuntos Sociales, quien a su vez asume su presidencia, y entre sus vocales figuran distintos altos cargos y otros órganos administrativos de la misma. Otro ejemplo lo representa, Vide Decreto 100/1998, de 26 de junio, por el que se regula la composición y funcionamiento de la Comisión Tutelar del Mayor legalmente incapacitado de Canarias. Vide Decreto 52/1996, de 9 de abril, por el que se crea la Comisión Tutelar de Adultos de Extremadura y se regula su composición y funcionamiento, art. 6. Esta Comisión dispondrá de un gabinete formado por personal técnico y un equipo administrativo, que será personal adscrito a la Consejería correspondiente.

91 Vide ORTEGA ÁLVAREZ, L., y JIMÉNEZ BLANCO, A. "Los sujetos de la relación jurídico-administrativa", en PAREJO ALFONSO, L., (Coord.), Manual de Derecho Administrativo, Ariel Derecho, Barcelona, 1990, p. 227.

92 Vide PÉREZ GÁLVEZ, J.F. Las agencias estatales para la mejora de los servicios públicos, Ed. Comares, Granada, 2007, pp. 22-23. 
ciertos organismos públicos acometerán las funciones a ellos atribuidos de forma específica, desempeñando el ejercicio de potestades o la realización de alguna actividad de las que ostentan su competencia ${ }^{93}$. Esta modalidad de intervención es frecuente en este ámbito habida cuenta de los problemas que suelen acompañar a la gestión directa en el ejercicio de la tutela, como la excesiva carga de trabajo, la insuficiencia de personal y la necesidad de una alta especialización en la materia, más propia del ámbito civil y, por tanto, no propia del régimen funcionarial. Estas entidades cuentan con personalidad jurídica pública diferenciada, patrimonio y tesorería propia y cierta autonomía de gestión, encontrándose participadas o controladas mayoritariamente por la Administración pública. Con carácter general, los organismos que habitualmente participarán en este sector serán los organismos autónomos y las entidades públicas empresariales ${ }^{94}$.

Junto a la intervención de estas entidades, cabe la posibilidad de que otras entidades de naturaleza mixta sometidas al protectorado ${ }^{95}$ de las Administraciones públicas, también se sumen a la función tutelar. Estas entidades cuentan con la protección y el respaldo de la Administración pública, como consecuencia del fin social que persiguen, atribuyéndose objetivos en consonancia con el interés general. Su status singular se debe por razones que apelan a sus orígenes históricos y/o compromisos internacionales del Estado español ${ }^{96}$. De forma específica, destaco la labor desempeñada por Cruz Roja Española ${ }^{97}$, que en el ámbito de la Comunidad Foral de Navarra, a través del convenio que suscribió con la Fundación navarra para la Tutela de

93 Vide PÉREZ GÁLVEZ, J.F. (2006):168-169.

${ }^{94}$ Vide Ley 6/1997, de 14 de abril, de Organización, Funcionamiento de la Administración General del Estado, art. 43. También forman parte las Agencias estatales, pero no desarrollan funciones específicas en este ámbito. Un ejemplo de organismos autónomos y entidades públicas empresariales como entidades tutelares, Vide: Estatutos del Instituto Almeriense de Tutela de la Excma. Diputación Provincial de Almería, BOP núm. 17, 27/01/2010; Ley 4/1995, de 21 de marzo, de creación de la Agencia Madrileña para la Tutela de Adultos.

95 Vide Estatutos de Cruz Roja Española, art. 1. Se define esta entidad como «una institución humanitaria de carácter voluntario y de interés público, que desarrolla su actividad bajo la protección del Estado español ejercida a través del Consejo de Protección [...]».

${ }^{96}$ Vide VAQUER CABALLERÍA, M. La acción social (Un estudio sobre la actualidad del Estado social de Derecho), Tirant Lo Blanch, Valencia, 2002, pp. 220-224.

${ }^{97}$ Fue fundada el 6 de julio de 1864 de acuerdo con la Conferencia Internacional de 26 de octubre de 1863, teniendo como objetivo general la difusión y aplicación de los Principios Fundamentales del Movimiento Internacional de Cruz Roja y Media Luna Roja. Vide: Estatutos de Cruz Roja Española, art. 5.7; Real Decreto 415/1996, de 1 de marzo, por el que se establece las normas de ordenación de la Cruz Roja española, art. 2. Su fin es «promover y colaborar en acciones de solidaridad $[\ldots]$ y de bienestar social en general y de servicios asistenciales y sociales, con especial atención a colectivos y personas con dificultades para su integración social». 
Personas Adultas, se convirtió en «colaborador tutelar», lo que implicó la posibilidad de que contribuyera mediante su propio personal (voluntario) en las funciones asignadas de acuerdo a los protocolos de actuación aprobados.

\section{Entidades privadas y el requisito de ausencia de lucro}

Tal y como avanzaba al inicio de este capítulo, la reforma del art. 242 Cc., a través de la Ley 13/1983, de 24 de octubre, introdujo la posibilidad de que también las personas jurídicas pudieran ser tutores de las personas incapacitadas. Este artículo determina que no todas las personas jurídicas podrán serlo, sino sólo aquéllas «que no tengan finalidad lucrativa y entre cuyos fines figure la protección de menores e incapacitados».

De este precepto se justifica no sólo que las entidades públicas pueden ejercer la institución tutelar, sino que también pueden hacerlo las entidades privadas. Ahora bien, entre las distintas entidades privadas que participan en el ámbito social y atendiendo a su naturaleza jurídica, sólo podrán ejercerla las entidades sin ánimo de lu$\mathrm{cro}^{98}$, quedando excluidas las entidades de iniciativa mercantil ${ }^{99}$. En el ámbito de la Comunidad Autónoma de Andalucía, la Ley 1/1999, de 31 de marzo, de atención a las personas con discapacidad, establece literalmente:

«La Administración de la Junta de Andalucía, promoverá, coordinada con la autoridad judicial, la atención a las personas presumiblemente incapaces o incapacitadas total o parcialmente, promoviendo entidades sociales sin ánimo de lucro que puedan desempeñar la tutela o curatela de aquéllas, de acuerdo con lo previsto en el Código Civil. Para ello impulsará la creación de entidades tutelares de ámbito territorial que garanticen el acercamiento al tutelado, cuidando su integración en su propio entorno».

La preferencia por las entidades sin ánimo de lucro en el ejercicio de la función tutelar no es nueva para el ámbito de la acción social. En este sector, la participación de estas entidades es imprescindible para una adecuada gestión y prestación de recursos sociales, por cuanto los poderes públicos son conscientes de la imposibilidad técnica y económica de poder llevar a cabo la prestación de tales recursos por sí mis-

98 Sobre los requisitos que se exigen para que una entidad sea considerada como entidad sin fines lucrativos, Vide Ley 49/2002, de 23 de diciembre, de régimen fiscal de las entidades sin fines lucrativos y de los incentivos fiscales al mecenazgo, art. 3.

99 Vide Ley 12/2007, de 11 de octubre, de Servicios Sociales de Cataluña, art. 69.3. En esta Comunidad Autónoma se determina que estas entidades podrán adoptar «cualquier forma societaria reconocida por la legislación mercantil». Vide Real Decreto Legislativo 1/2010, de 2 de julio, por el que se aprueba el texto refundido de la Ley de Sociedades de Capital. 
$\operatorname{mos}^{100}$. Estas entidades, son consideradas como entidades prestadoras ${ }^{101}$ o colaboradoras ${ }^{102}$ del sistema público de servicios sociales, a las que con carácter prioritario $^{103}$ o preferente ${ }^{104}$, se les reconoce el derecho de participación ${ }^{105}$. Las legislaciones autonómicas sobre esta materia dedican una parte de su articulado a la regulación de forma pormenorizada de estas entidades. Además de reconocerles el derecho, se fomenta ${ }^{106}$ su participación mediante un programa específico de subvenciones, o incluso de otros medios de carácter técnico ${ }^{107}$ para apoyar el desarrollo de las iniciativas de solidaridad social ${ }^{108}$.

La realidad presenta un variadísimo conjunto de entidades sin ánimo de lucro como entidades prestadoras de recursos sociales (asociaciones, fundaciones, organizaciones religiosas, obras sociales, cooperativas, etc.), si bien respecto al ámbito tutelar de personas incapacitadas, la tendencia de la Administración pública ha sido la de promover personas jurídicas de tipo fundacional, por lo que la Fundación se convierte en la forma jurídica más utilizada como entidad tutelar, y su composición ostenta un carácter mixto (entidades públicas y privadas).

Su grupo normativo regulador lo constituyen las siguientes disposiciones: a) La Constitución Española que reconoce el derecho de fundación (art. 34); b) El Código Civil, que reconoce a la fundación como una «persona jurídica de interés público» ${ }^{109}$; c) La Ley 50/2002, de 26 de diciembre, sobre Fundaciones; d) La Ley 49/2002, de 23 de diciembre, del régimen fiscal de las entidades sin fines lucrativos y de los incentivos fiscales al mecenazgo. También he de señalar la amplia regulación existente en el ámbito de las CCAA, pues todas han asumido como competencia ex-

100 Vide MIGUEZ MACHO, L. "La transformación del régimen jurídico de los servicios sociales", Revista española de Derecho Administrativo, 153, (2012), p. 53.

101 Vide Ley 13/2008, de 3 de diciembre, de Servicios Sociales de Galicia, art. 66.2 c).

102 Vide: Ley 12/2007, de 11 de octubre, de Servicios Sociales de Cataluña, art. 77; Ley 11/2003, de 27 de marzo, de Servicios Sociales de la Comunidad de Madrid, art. 58.

103 Vide: Ley 12/2008, de 5 de diciembre, de Servicios Sociales del País Vasco, art. 65; Vide Ley 16/2010, de 20 de diciembre, de Servicios Sociales de Castilla y León, art. 87.2.

104 Vide: Ley 14/2010, de 16 de diciembre, de Servicios Sociales de Castilla La Mancha, art. 28; Ley 11/2003, de 27 de marzo, de Servicios Sociales de la Comunidad de Madrid, art. 56.

105 Vide BARRANCO VELA, R. "El principio de participación en las Leyes de Servicios Sociales", Alternativas: Cuadernos de Trabajo Social, (1993), p. 246.

106 Vide: GARRIDO FALLA, F., y otros. (2006): 377; VILLAR ROJAS, F.J. (2005): 396.

107 Vide Ley 9/1987, de 28 de abril, de Servicios Sociales de Canarias, art. 15.

108 Vide Ley 1/2003, de 24 de febrero, de Servicios Sociales del Principado de Asturias, art. 44.

${ }^{109}$ Vide PIÑAR MAÑAS, J.L. Régimen jurídico de las fundaciones: jurisprudencia del Tribunal Constitucional y del Tribunal Supremo, Ministerio de Asuntos Sociales, Madrid, 1993, p. 29. 
clusiva su regulación a través de los Estatutos de Autonomía ${ }^{110}$ y publicado normas legislativas y/o reglamentarias en su desarrollo ${ }^{11}$.

Las fundaciones ${ }^{112}$ como instituciones sin ánimo de lucro, son creadas por particulares, que poniendo a disposición de fines de interés general ${ }^{113}$ sus propios bienes, determinan a través de sus Estatutos, las condiciones que desean que rijan para el gobierno y la administración de la misma (protectorado) ${ }^{114}$, siempre dentro del marco legal ${ }^{115}$. Se tratan, por tanto, de entidades con personalidad jurídica privada cuya intervención en este ámbito se fundamenta en la libre actividad de prestación reconocida por las leyes de acción social, con voluntad de permanencia y como actividad prioritaria la protección de personas incapacitadas. En el ámbito autonómico podemos encontrar multitud de estas fundaciones tutelares, cuyo rasgo característico es que en el protectorado (control, vigilancia, gobierno y administración) se encuentren las Administraciones públicas (autonómicas o locales), al tiempo que otras entidades de acción social que colaboran en la protección de las personas incapacitadas.

\section{Funciones y competencias}

Hemos visto que el art. 242 Cc., exige a las personas jurídicas que desarrollen funciones tutelares, el que aparezca entre sus fines la protección de las personas incapacitadas. Esto significa que este fin no tiene por qué ser el único al que se dedica la entidad tutelar, pues puede compartir otras funciones propias del ámbito social o proyectar su actuación sobre otros sectores con necesidad de protección. De lo que no dudamos es sobre la obligación de que entre los fines que deben figurar en la norma

${ }^{110}$ A modo de ejemplo, Vide: Estatuto de Autonomía de Andalucía (art. 79), Aragón (art. 71.40), Castilla y León (art. 70.34), Cataluña (art. 118), Extremadura (art. 7.26), País Vasco (art. 10.13), etc.

111 Entre otras, Vide: Ley 10/2005, de 31 de mayo, de Fundaciones de Andalucía; Decreto 32/2008, de 5 de febrero, por la que se aprueba el Reglamento de Fundaciones de Andalucía; Ley Foral 10/1996, de 2 de julio, reguladora del régimen tributario de las funciones y de las actividades de patrocinio; Decreto Foral 613/1996, de 11 de noviembre, de la Consejería de Presidencia e Interior, por el que se regula la estructura y el funcionamiento del Registro de Fundaciones.

112 Vide: PÉREZ GÁLVEZ,J.F. (2006): 463-468.

113 Vide: Ley 50/2002, de 26 de diciembre, de Fundaciones, art. 3. Entre ellos, la promoción de la acción social y la protección de personas en situación de exclusión. Vide MORALES, J. (1998): 69.

114 Vide PIÑAR MAÑA, J.L. (1993): 18.

115 Vide DE LORENZO GARGIA, R., y CABRA DE LUNA, M.A. "Las fundaciones", en AA.VV., El sector no lucrativo en España, Escuela Libre Editorial, Madrid, 1993, p. 55. Tres elementos son característicos de toda fundación: patrimonio, organización y fin. 
de creación de la entidad, ya sea una norma legal, reglamentaria o estatutaria ${ }^{116}$, la protección de las personas incapacitadas deba aparecer, sin perjuicio de que sea necesario una mayor concreción en torno a delimitar las funciones y actividades que la entidad va a desarrollar.

Cuando hablamos de proteger a las personas incapacitadas judicialmente, las funciones propias de las personas jurídicas se estructuran en base a dos criterios de protección: por un lado, la protección personal y patrimonial que afecta a sus condiciones de vida y dignidad personal, proporcionando protección y defensa tanto a las personas incapacitadas judicialmente como las que están en proceso de incapacitación. Esto conlleva el ejercicio inexcusable de las instituciones tutelares ${ }^{117}$ de las personas mayores de edad, y de las medidas provisionales que en estos procesos se dicten por la autoridad judicial competente. En este contexto también se prevé la administración de los bienes de su patrimonio actuando en su beneficio, que implica atender a los principios de prudencia, conservación y mejora de éstos ${ }^{118}$. Por otro lado, también es fundamental la protección social, que promueve un mayor nivel de autonomía personal y plena integración y normalización de los tutelados, facilitando recursos sociales, la atención personal del incapacitado, su cuidado, rehabilitación, etc.

Debe indicarse que desde estas entidades, no sólo se atiende a las personas incapacitadas legalmente, sino que también, entre sus funciones, se encuentra la de prestar información, orientación, asesoramiento y asistencia a padres, familiares y otros tutores, o incluso, profesionales externos, esto es, informar y asesorar sobre qué hacer, dónde ir, cómo actuar, etc., ante posibles casos de incapacitación ${ }^{119}$.

Para el logro de estas funciones, las personas jurídicas tienen la capacidad de promover el establecimiento de convenios y protocolos de actuación y coordinación de sus actividades entre instituciones públicas y privadas que se dediquen a fines similares y suscribir contratos con personas físicas o jurídicas (públicas o privadas) para el mejor cumplimiento de estos fines ${ }^{120}$.

116 Vide BARRERO RODRÍGUEZ, G. "Algunas consideraciones sobre los fines de las fundaciones y su garantía por la Administración", Revista andaluza de Administración Pública, 183, (2000), p. 78. En opinión de esta autora, en los Estatutos de las fundaciones se configuran fines abiertos e inacabados ya que no hay una imposición que obligue a delimitar de forma exacta la finalidad de los mismos en sus Estatutos.

117 Vide Cc., art. 215 y ss.

118 Vide Ley 4/1995, de 21 de marzo, por la que se crea la Agencia madrileña para la tutela de Adultos, art. 4.

119 Vide Dirección General de Personas con Discapacidad, Protocolo de actuación de las entidades tutelares en Andalucía, 2012, pp. 17-18.

${ }^{120}$ Vide Decreto 52/1996, de 9 de abril, por el que se crea la Comisión Tutelar de Adultos de Extremadura y se regula su composición y funcionamiento, art. 4. 


\section{INTERVENGIÓN ADMINISTRATIVA EN LA PRESTACIÓN DE REGURSOS SOGIALES}

Tal y como hemos visto anteriormente, la Administración pública desempeña una doble función: por un lado, tutela o promueve la misma a través de diferentes entidades tutelares, principalmente fundaciones y, por otro lado, ha de proteger socialmente a las personas adultas mediante un sistema público de recursos sociales. Sobre este aspecto, he de indicar que no es frecuente que las entidades tutelares lo sean también prestacionales, por tanto, entre las funciones que he señalado en el apartado anterior, se encuentra el de proveer, como entidades responsables de la persona incapacitada, el recurso que mejor se adapte a las necesidades del tutelado. Para ello, iniciará los procedimientos administrativos correspondientes a fin de que la persona incapacitada acceda al sistema público de recursos sociales dotándole de los adecuados mecanismos de garantía y protección necesarios atendiendo a su discapacidad y/o dependencia.

En los próximos epígrafes veremos no sólo cuáles son los recursos sociales a los que pueden tener acceso las personas adultas, sino que analizaremos brevemente, los requisitos jurídico-administrativos que tienen que cumplir las entidades prestacionales que sin tutelar a las personas incapacitadas, intervienen en este ámbito gestionando los recursos sociales que sí les ofertan.

\section{Recursos sociales frente a la incapacidad}

Una de las características de la acción social era el entenderla como una actividad prestacional, que justifica la intervención de la Administración pública a través de la provisión de recursos sociales. Estas prestaciones, en palabras de BELTRÁN AGUIRRE, «constituyen el objeto ordinario de los servicios públicos administrativos y, desde luego, de los servicios públicos asistenciales» ${ }^{121}$. En esta investigación distinguiré entre prestaciones de servicio y prestaciones económicas.

\section{A. Prestaciones de servicio}

Para comprender la tipología de prestaciones de servicio que se ofrecen a los ciudadanos, ha de diferenciarse los centros de los servicios sociales. Los centros son la estructura física, bien inmueble, de titularidad pública o privada que da soporte a los diversos programas o actividades que se planifican, en consecuencia, ostentan una naturaleza meramente instrumental. Los servicios sociales ostentan una naturaleza jurídica de servicio público de carácter prestacional, constituyen en sí mismos, el re-

${ }^{121}$ Vide BELTRÁN AGUIRRE, J.L. (1992): 263. 
curso de atención concreto o programa específico que da cumplimiento a los objetivos propios de la acción social. La tipología de centros y servicios sociales ofrece la posibilidad de su clasificación atendiendo a numerosos criterios, como por su titularidad (públicos o privados), su carácter (socioeducativos, socioculturales o sociosanitarios), su finalidad (asistenciales, rehabilitadores y/o de reinserción social o de integración social), etc. Atendiendo a las diferentes posibilidades que pueden darse en el ámbito de las CCAA, los sistemas públicos de servicios sociales contemplan, por un lado, centros y servicios públicos pertenecientes a la Administración pública, sus organismos y entidades dependientes (autonómicas o locales) y, por otro lado, centros y servicios privados concertados con entidades de iniciativa social (sin ánimo de lucro) y de iniciativa mercantil (con ánimo de lucro) ${ }^{122}$. En todo caso, los centros y servicios privados deberán estar acreditados ${ }^{123}$.

La Ley 39/2006, de 14 de diciembre, de Promoción de la Autonomía Personal y Atención a las personas en situación de dependencia, establece el siguiente catálogo de servicios ${ }^{124}$ :

\section{Servicio de prevención de las situaciones de dependencia ${ }^{125}$ :}

Este servicio previene la aparición o el agravamiento de enfermedades o discapacidades y de sus secuelas. Como consecuencia de las diferentes actuaciones que comporta es precisa una adecuada coordinación entre los servicios sociales y los servicios de salud. Tales actuaciones conllevan: a) Promoción de condiciones de vida saludables; b) Programas específicos de carácter preventivo; c) Programas de rehabilitación dirigidos a personas mayores y personas con discapacidad ${ }^{126}$.

122 Vide ANGUAS ORTIZ, L.F. "El sistema para la autonomía y atención a la dependencia en la Comunidad Autónoma de Andalucía”, en FERNÁNDEZ RAMOS, S., y PÉREZ MONGUIÓ, J.M., (Coord.), El Derecho de los servicios sociales en Andalucia, Instituto Andaluz de Administración Pública, Sevilla, 2012, p.

123 Vide Ley 39/2006, de 14 de diciembre, de Promoción de la Autonomía Personal y Atención a las personas en situación de dependencia, art. 16.

${ }^{124}$ Vide: Ley 39/2006, de 14 de diciembre, de Promoción de la Autonomía Personal y Atención a las personas en situación de dependencia, art. 15; ANGUAS ORTIZ, L.F. (2012): pp. 613-618.

125 Vide Ley 39/2006, de 14 de diciembre, de Promoción de la Autonomía Personal y Atención a las personas en situación de dependencia, art. 21.

126 Vide ALONSO SECO, J.M., y FERNÁNDEZ SANTIAGO, P. "El sistema público de servicios sociales", en ALEMÁN BRACHO, G., (Coord.), Fundamentos de servicios sociales, Tirant Lo Blanch, Valencia, 2010, pp. 271-272. Vide Decreto 56/2011, de 20 de mayo, de la Consejería de Asuntos Sociales, Promoción e Inmigración, por el que se aprueba la Cartera Básica de Servicios Sociales de Islas Baleares 2011-2014, Anexo. 
Su desarrollo se efectúa en los servicios de atención de día, residenciales, ayuda a domicilio, etc.

\section{Servicio de promoción de la autonomía personal:}

Este servicio tiene por finalidad desarrollar y mantener la capacidad personal de controlar, afrontar y tomar decisiones acerca de cómo vivir de acuerdo con las normas y preferencias propias y facilitar la ejecución de las actividades básicas de la vida diaria ${ }^{127}$.

Así por ejemplo, son servicios de promoción, los de habilitación y terapia ocupacional, la estimulación cognitiva, la promoción, mantenimiento y recuperación de la autonomía funcional, la habilitación psicosocial para personas con enfermedad mental o discapacidad intelectual, etc. Junto a estos servicios, se prevén otras acciones complementarias que pueden ser desarrolladas por las CCAA, como las de asesoramiento (recabando documentación, etc.), acompañamiento activo (gestión de prestaciones), orientación, asistencia y formación en tecnologías de apoyo y adaptaciones, etc., cuya finalidad es la de facilitar la realización de las actividades de la vida diaria.

\section{Servicio de teleasistencia:}

El servicio de teleasistencia domiciliaria es otro de los servicios sociales básicos o comunitarios que se encuentran más arraigados entre la población. Este servicio permite asegurar una respuesta inmediata ante situaciones de emergencia, o de inseguridad, soledad o aislamiento. Está previsto que se pueda prestar de forma autónoma o de forma complementaria a otros servicios ${ }^{128}$, como el servicio de ayuda a domicilio, favoreciendo la permanencia del usuario en su lugar de residencia.

Todas las CCAA contemplan el servicio de teleasistencia ${ }^{129}$ en su catálogo de servicios sociales ${ }^{130}$. Consiste en un entorno informático con un terminal que se en-

127 Vide Real Decreto 1051/2013, de 27 de diciembre, que regula las prestaciones del Sistema de Autonomía y Atención a la Dependencia, art. 6.

128 Vide Ley 39/2006, de 14 de diciembre, de Promoción de la Autonomía Personal y Atención a personas en situación de Dependencia, art. 22.

129 Vide PÉREZ GÁLVEZ, J.F. "Administración sanitaria y telemedicina”, Actualidad administrativa, 27, (2003), pp. 669-699.

${ }^{130}$ A modo de ejemplo, Vide: Orden de 10 de enero de 2002, de la Consejería de Asuntos Sociales, por la que se regula el Servicio Andaluz de Teleasistencia; Orden de 22 de enero de 2003, de la Consejería de Bienestar Social, por la que se regulan y actualizan las prescripciones técnicas y el baremo de acceso del servicio de ayuda a domicilio y Teleasistencia de Castilla La Mancha. 
cuentra en el domicilio de la persona usuaria del servicio ${ }^{131}$. La persona lleva un dispositivo sobre sí que, al pulsarlo, desencadena una señal de alarma identificable en la central de escucha, donde, de manera automática, se muestra en el ordenador del operador/a los datos identificativos y relevantes del usuario o usuaria. Inmediatamente, se produce el contacto telefónico para detectar la causa de la llamada y buscar la solución más pertinente, incluyendo, si el caso lo requiere, el envío de ayuda urgente al domicilio de donde proviene la señal de alarma ${ }^{132}$.

\section{Servicio de ayuda a domicilio:}

El servicio de ayuda a domicilio es uno de los servicios sociales más importantes y demandados en la actualidad, a lo que mucho ha tenido que ver su reconocimiento y consolidación como derecho subjetivo por la Ley de Dependencia ${ }^{133}$. Se trata de un servicio público caracterizado por ser polivalente, domiciliario, preventivo, técnico y rehabilitador, cuyas actuaciones son llevadas a cabo en el propio domicilio. Es un servicio compatible con otros servicios sociales como el de teleasistencia y el de centro de día. La intensidad del servicio se mide en horas de atención, que vienen establecidas a través del Programa Individual de Atención.

Este servicio atiende las necesidades básicas de la vida diaria incrementando su autonomía. Estas necesidades comprenden dos actuaciones: a) Las que atienden las necesidades domésticas o del hogar, como la alimentación, el vestido o el mantenimiento de la vivienda; b) Las que atienden las necesidades de atención personal, como la higiene personal, la movilidad, la ayuda familiar y social, algunos cuidados especiales como el control de medicamentos, etc ${ }^{134}$.

\section{Servicio de centro de día y de noche:}

El servicio de centro de día y de noche constituye un servicio no continuado, pues se presta sólo durante una parte del día, ya sea en período diurno o nocturno. Este servicio ofrece una atención integral a través de servicios de manutención, ayuda a

131 Vide: MORENO REBATO, M. (2002): 207; ALEMÁN BRACHO, C., ALONSO SECO, J.M., y GARCÍA SERRANO, M. Servicios sociales públicos, Tecnos, Madrid, 2011, p. 245.

132 Vide: MINISTERIO DE TRABAJO Y ASUNTOS SOCIALES, Libro Blanco. Atención a las personas en situación de dependencia en España, Subdirección General de Publicaciones del Ministerio, Madrid, 1997, p. 374; ALONSO-OLEA GARCÍA, B., y MEDINA GONZÁLEZ, S. Derecho de los Servicios Públicos Sociales, Civitas, Cizur Menor, 2011, p. 137.

133 Vide Ley 39/2006, de 14 de diciembre, de Promoción de la Autonomía Personal y Atención a personas en situación de Dependencia, art. 23.

134 Vide Decreto 42/2000, de 18 de mayo, de la Consejería de Asuntos Sociales, por el que se regula la ayuda a domicilio en el Principado de Asturias, art. 14. 
las actividades diarias, terapia ocupacional, acompañamiento y otros ${ }^{135}$, con el objetivo de mejorar la calidad de vida tanto del usuario, a través del mantenimiento o mejora de su autonomía personal ${ }^{136}$, como de los cuidadores a los que permite no sólo su descanso sino compatibilizar el cuidado de su familiares con las obligaciones laborales $^{137}$. En el ámbito de la Comunidad Autónoma de Andalucía, se distingue entre servicios de centro de día dirigidos a personas mayores y servicios de centro de día dirigidos a personas con discapacidad ${ }^{138}$.

\section{Servicio de atención residencial:}

El servicio de atención residencial ofrece una atención multidisciplinar, integral y continuada, de carácter personal tanto social como sanitaria ${ }^{139}$. Se tiene en cuenta la naturaleza de la dependencia y el grado e intensidad de cuidados que precise la persona $^{140}$, pudiendo tener carácter permanente o temporal.

135 Vide Decreto 388/2010, de 19 de octubre, por el que se regula el régimen de acceso y traslado de personas en situación de dependencia a plazas de centros residenciales y centros de día y de noche en Andalucía, art. 3.

136 Vide Orden de 6 de mayo de 2002, de la Consejería de Asuntos Sociales, por la que se regula el acceso y el funcionamiento de los programas de estancia diurna y respiro familiar en Andalucía, art. 2.a).

137 Vide Ley 39/2006, de 14 de diciembre, de Promoción de la Autonomía Personal y Atención a personas en situación de Dependencia, art. 24.

138 Vide Orden 1 de octubre de 2007, por la que se aprueban los modelos de informe social, trámite de consulta y propuesta de programa individual de atención del sistema para la autonomía y atención a la dependencia en Andalucía, Anexo III. En los centros de día para personas mayores, el perfil de acceso es de persona mayor de 65 años que no necesite permanecer en cama. Los centros de día para personas con discapacidad comprenden a menores de dicha edad que reúnan ciertos requisitos: a) Que por su gravedad o continuidad de cuidados no puedan atenderse en casa; b) Que atendiendo a su grado de discapacidad, no puedan integrarse transitoria o permanentemente en un medio laboral especial o normalizado; c) Que se encuentre afectada por alguna de las siguientes discapacidades: intelectual, física, visual, parálisis cerebral, trastornos del espectro autista, alteraciones graves de conducta, daño cerebral, etc. Vide Orden de 09/03/2011, de la Consejería de Salud y Bienestar Social, por la que se establece el régimen jurídico y el sistema de acceso a los servicios de estancias diurnas en centros pertenecientes a la red pública de Castilla La Mancha, art. 2.2. En esta Comunidad Autónoma se distingue entre servicios de estancias diurnas generales y específicos, estando destinados estos últimos a la atención de personas con enfermedad tipo Alzheimer, u otro tipo de demencias o alteraciones importantes de la capacidad cognitiva, y a su vez puedan estar acompañados de otros trastornos psicopatológicos o de conducta.

${ }^{139}$ Vide Ley 39/2006, de 14 de diciembre, de Promoción de la Autonomía Personal y Atención a personas en situación de Dependencia, art. 25.

140 Vide Real Decreto 1051/2013, de 27 de diciembre, por el que se regulan las prestaciones del Sistema para la Autonomía y Atención a la Dependencia, establecidas en la Ley 39/2006, de 14 de diciembre, de Promoción de la Autonomía Personal y Atención a las personas en situación de dependencia, art. 10 . 
Los servicios que ofrece se estructuran en los siguientes servicios: a) Servicios básicos, que comprende el alojamiento, la manutención o comedor, la higiene y el aseo personal; b) Servicios terapéuticos, que son desarrollados por personal cualificado (médicos, enfermeros, fisioterapeutas, etc.) y comprende la atención sanitaria (seguimiento y cuidado sanitario, dotación de material sanitario, prescripción y administración de medicamentos, etc.), atención social (mejora de las condiciones físicas, desequilibrios y ajustes psíquicos, adaptación al colectivo de residentes, etc.), atención psicológica (prevención o tratamiento de trastornos conductuales, evaluación e intervención en el dolor crónico, etc.) y, atención educativa (refuerzo por falta de maduración social, orientación psicopedagógica, etc.).

En el ámbito de la Comunidad Autónoma de Andalucía, se distingue entre los dos siguientes servicios de atención residencial: el de personas mayores en situación de dependencia y el de personas con discapacidad en situación de dependencia ${ }^{141}$ (extensivas, por tanto, a las personas incapacitadas judicialmente). Respecto a las primeras, se distingue entre el servicio de atención residencial en centros para personas mayores asistidas, cuyo perfil de entrada son personas mayores de 65 años en situación de dependencia en su grado II ó III y, el servicio de atención residencial en psicogeriátricos para personas mayores, dirigido a los anteriores pero que además ofrecen trastornos graves y continuados de conducta.

Respecto al servicio de atención residencial para personas con discapacidad en situación de dependencia, se tiene en cuenta el grado de discapacidad (tipo de enfermedad, etc.), la problemática socio-familiar y económica, las dificultades para ser atendido en su lugar de convivencia, la imposibilidad de vivir solos, etc. El perfil de acceso es estar valorado en un grado de dependencia II ó III, tener una discapacidad intelectual, física, parálisis cerebral, trastornos del espectro autista, etc., y estar comprendido entre los 16 y 65 años, salvo que presente una discapacidad intelectual. La clasificación que ofrece esta Comunidad Autónoma está establecida por la Orden de 1 de octubre de 2007, por la que se aprueban los modelos de informe social, trámite de consulta y propuesta de programa individual de atención del sistema para la autonomía y atención a la dependencia en Andalucía, y que por su relevancia describo a continuación ${ }^{142}$ :

${ }^{141}$ Vide Orden 1 de octubre de 2007, por la que se aprueban los modelos de informe social, trámite de consulta y propuesta de programa individual de atención del sistema para la autonomía y atención a la dependencia en Andalucía, Anexo III.

142 Vide

http://www.juntadeandalucia.es/organismos/igualdadsaludypoliticassociales/areas/dependencia /prestaciones / paginas/atencion-residencial.html. 
Servicio de atención residencial para personas gravemente afectadas por discapacidad intelectual: este servicio atiende de forma integral a personas con discapacidad intelectual que precisen la ayuda generalizada de otras personas para realizar las actividades de la vida diaria y que no pueden ser atendidas en su unidad de convivencia.

Servicio de atención residencial para personas adultas: presta una atención integral a personas con discapacidad con cierta autonomía personal que tienen dificultadas para la integración social y familiar en su unidad de convivencia.

Servicio de atención residencial para personas gravemente afectadas por discapacidad física y/o visual o parálisis cerebral: se atiende de forma integral a personas con discapacidad física y/o parálisis cerebral que precisen la ayuda generalizada de otras personas para realizar las actividades de la vida diaria y que no pueden ser atendidas en su unidad de convivencia.

Servicio de atención residencial para personas con trastorno del espectro autista: este servicio atiende de forma integral a personas con trastorno del espectro autista que precisen la ayuda de otras personas para realizar las actividades de la vida diaria y que no pueden ser atendidas en su unidad de convivencia.

Servicio de atención residencial para personas psicodeficientes: está orientado hacia aquellas personas con discapacidad intelectual con alteraciones graves y continuadas de conducta que no remiten con tratamiento ambulatorio y/o en unidades de agudos, y cuyas circunstancias familiares, sociales y económicas son tan graves que no pueden ser atendidas por su unidad de convivencia.

Servicio de atención residencial en casas-hogar para personas con enfermedad mental: es un servicio dirigido a personas con escaso nivel de autonomía personal como consecuencia de una enfermedad mental, debiendo garantizar la cobertura de sus necesidades de atención no sanitaria y con una función sustitutoria del hogar familiar.

Servicio de atención residencial en viviendas tuteladas para personas con discapacidad: son unidades de alojamiento ubicadas en edificios o zonas de vivienda normalizadas destinadas a aquellas personas con discapacidad con un grado suficiente de autonomía, y que tengan dificultad para una integración social y familiar en su unidad de convivencia.

Servicio de atención residencial en viviendas supervisadas para personas con enfermedad mental: son unidades de alojamiento y convivencia ubicadas en edificios o zonas de viviendas normalizadas, destinadas a personas con enfermedad 
mental que posean un grado suficiente de autonomía personal, por lo que no precisan personal específico durante las 24 horas. Cuentan con la distribución de espacios de una vivienda familiar y están dotadas de todo el equipamiento y servicios necesarios para las personas que las habitan.

\section{B. Prestaciones económicas}

Las prestaciones de carácter económico constituyen otras de las prestaciones reguladas por la mayor parte de las normas autonómicas en materia de acción social. Estas prestaciones están configuradas como subsidiarias ${ }^{143}$ y complementarias ${ }^{144}$ a las prestaciones de servicio que se acaban de señalar. Las prestaciones económicas son definidas como aquellas aportaciones dinerarias, que tienen como finalidad atender a determinadas situaciones de necesidad en que se hallan las personas que no disponen de recursos económicos suficientes para afrontarlas y no están en condiciones de conseguirlos o recibirlos de otras fuentes ${ }^{145}$. Entre las más importantes citaré las siguientes:

\section{Pensiones no contributivas de invalidez y jubilación:}

Son prestaciones cuya gestión se encuentra delegada a las CCAA. Se crearon por Ley 26/1990, de 20 de diciembre, y en la actualidad su regulación se efectúa a través del Real Decreto Legislativo 1/1994, de 20 de junio, por el que se aprueba el Texto Refundido de la Ley General de la Seguridad Social. Se conceden a personas que o bien no han cotizado nunca, o no han llegado a los límites establecidos reglamentariamente, para tener derecho a una determinada pensión ${ }^{146}$.

Presentan los siguientes rasgos característicos: a) Son percibidas por personas que carecen de recursos suficientes, es decir, no disponen de otros ingresos, y de percibirlos son mínimos; b) Los beneficiarios no han cotizado nunca a la seguridad social

143 Vide: GARGÉS SANAGUSTÍN, A. La Acción Social: delimitación conceptual y régimen jurídico, Diputación General de Aragón, Zaragoza, 1988, p. 132; Ley 2/2007, de 27 de marzo, de Derechos y Servicios Sociales de Cantabria, art. 28.2; Ley 16/2010, de 20 de diciembre, de Servicios Sociales de Castilla y León, art.18.

${ }^{144}$ Vide: GARCÉS SANAGUSTÍN, A. "Las prestaciones dinerarias: en particular, los ingresos mínimos de inserción y el debate sobre la renta básica", Documentación Administrativa, 27 1-272, (2005), p. 442; Ley 5/1997, de 25 de junio, del Sistema de Servicios Sociales de la Comunidad Valenciana, art. 37.

145 Vide: Ley 12/2007, de 11 de octubre, de Servicios Sociales de Cataluña, art. 22.1; Ley 4/2009, de 11 de junio, de Servicios Sociales de las Islas Baleares, art. 22; Ley 11/2003, de 27 de marzo, de Servicios Sociales de la Comunidad de Madrid, art.17, entre otras.

146 Vide MORENO REBATO, M. (2002): 130. 
y si lo han hecho, ha sido de forma insuficiente; c) Han de cumplir con los requisitos legalmente establecidos, que para el caso de la pensión no contributiva de invalidez, es la de tener reconocido un grado de discapacidad de al menos el 65\%; y en el caso de la pensión no contributiva, tener cumplidos los 65 años.

\section{Subsidios derivados de la Ley de Integración Social de Minusválidos:}

Estos subsidios fueron regulados por la Ley de Integración Social de Minusválidos ${ }^{147}$, y se subdividen en cuatro modalidades: a) Subsidio de garantía de ingresos mínimos: que consiste en una prestación económica destinada a cubrir las necesidades básicas de las personas con discapacidad (al menos el 65\% de grado de discapacidad), que carezcan de medios suficientes; b) Subsidio por ayuda de tercera persona: que es una prestación económica destinada a atender los gastos de las personas con discapacidad (al menos el 75\% de grado de discapacidad), por necesitar la asistencia de otra persona para realizar los actos esenciales de la vida diaria; c) Subsidio de movilidad y compensación por gastos de transporte: en este caso se trata de una prestación económica destinada a atender gastos de desplazamiento cuando, por razón de discapacidad (al menos un 33\% de grado de discapacidad), existen graves dificultades para utilizar transportes colectivos; d) Finalmente, la asistencia sanitaria y prestación farmacéutica: que consiste en una prestación de servicio médico-sanitario y farmacéutico gratuito para personas con discapacidad (al menos 33\% de grado de discapacidad), que carezcan de cobertura médica y farmacéutica por cualquier otro concepto.

No obstante, tanto el Subsidio de Garantía de Ingresos Mínimos (SGIM) como el Subsidio de Ayuda por Tercera Persona (SATP), fueron derogados en el año 1991, con la entrada en vigor de la disposición reguladora de las Pensiones No Contributivas, por lo que actualmente no puede accederse a ellos. No obstante, la persona que ya es beneficiaria puede seguir percibiendo estos subsidios siempre que continúe reuniendo los requisitos exigidos por el que se le concede el derecho ${ }^{148}$.

\section{Pensiones asistenciales por ancianidad y enfermedad:}

Son prestaciones económicas a favor de personas cuyos ingresos propios o familiares son insuficientes para cubrir las necesidades básicas ${ }^{149}$. Estas ayudas asisten-

147 Vide TORRES LÓPEZ, M.A. La discapacidad en el Derecho Administrativo, Civitas Thomson Reuters, Cizur Menor, 2011, p. 119.

148 Vide GARCÉS SANAGUSTÍN, A. (2005): 443.

${ }^{149}$ Vide Real Decreto 2620/1981, de 24 de julio, de la Presidencia del Gobierno, por el que se regula la concesión de ayudas del Fondo Nacional de Asistencia Social a ancianos y a enfermos o inválidos incapacitados para el trabajo, art. 1.2.a). 
ciales, que fueron creadas en 1960, ya no pueden solicitarse, puesto que fueron derogadas en el año $1992^{150}$. No obstante, la persona que ya es beneficiaria puede seguir percibiéndola siempre que continúe reuniendo los requisitos exigidos para concederle el derecho ${ }^{151}$.

\section{Prestaciones económicas de carácter complementario:}

En el ámbito de sus respectivas competencias, tanto a nivel estatal como a nivel autonómico, se articulan también una serie de prestaciones económicas que tienen como finalidad aumentar la capacidad económica de quienes perciben alguna prestación económica asistencial. Su objetivo, por tanto, es mejorar el bienestar de los ciudadanos, complementando la prestación que perciben, por entender que la misma es manifiestamente mejorable, en atención a sus necesidades básicas. Un ejemplo de estas prestaciones, lo representa a nivel estatal, las ayudas reguladas por el Real Decreto 1191/2012, de 3 de agosto, por el que se establecen normas para el reconocimiento del complemento de pensión para el alquiler de vivienda a favor de los pensionistas de la Seguridad Social en su modalidad no contributiva.

\section{Prestaciones económicas derivadas de la Ley 39/2006, de 14 de di- ciembre, de Promoción de la Autonomía Personal y Atención a personas en situación de Dependencia ${ }^{152}$ :}

La Ley de Dependencia prevé la posibilidad de acceso a prestaciones económicas $^{153}$. La finalidad de estas prestaciones va dirigido a un doble sentido: por una parte, a la promoción de la autonomía personal y, por otra, a atender las necesidades de las personas con dificultades para la realización de las actividades básicas de la vida diaria $^{154}$.

${ }^{150}$ La entrada en vigor del Real Decreto 357/1991, de 15 de marzo, permite a los beneficiarios de estas pensiones, si reúnen los requisitos exigidos para ello, optar entre mantener estas prestaciones o pasar a percibir una pensión no contributiva de invalidez, jubilación o asignación económica por hijo con discapacidad a cargo [prestaciones establecidas en la Ley 26/1990, de 20 de diciembre, por la que se establecen en la Seguridad Social prestaciones no contributivas. Las pensiones asistenciales quedan derogadas a partir de la entrada en vigor del R.D. Ley 5/1992, de 21 de julio -posteriormente derogado por la Ley 28/1992, de 24 de noviembre-, sin afectar a las pensiones ya reconocidas o pendientes de resolución.

151 Vide Real Decreto Ley 5/1992, de 21 de julio, de Medidas Presupuestarias Urgentes, art. 7.

152 Vide ANGUAS ORTIZ, L.F. (2012): 618-624.

153 Vide Ley 39/2006, de 14 de diciembre, de Promoción de la Autonomía Personal y Atención a personas en situación de Dependencia, art. 14.1.

${ }^{154}$ Vide DE LORENZO GARCÍA, R., y PALACIOS, A. (2005): 333. 
Son prestaciones reconocidas por la Ley de Dependencia y garantizadas en las CCAA, a través de sus sistemas públicos de servicios sociales, las siguientes ${ }^{155}$ : Prestación Económica Vinculada al Servicio, que consiste en una prestación económica, de carácter periódico, que se podrá reconocer cuando no sea posible el acceso a una prestación de servicio público o concertado (las cantidades abonadas en este concepto estarán vinculadas a la adquisición del correspondiente servicio); Prestación Económica para Cuidados en el Entorno Familiar y apoyo a cuidadores no profesionales, se trata de una prestación económica, de carácter periódica y excepcional, que se podrá conceder cuando el beneficiario esté siendo atendido por su entorno familiar, y se reúnan condiciones adecuadas de convivencia y de habitabilidad de la vivienda; Prestación Económica de Asistencia Personal, que tiene como finalidad la promoción de las personas en situación de Gran Dependencia.

\section{Ingresos mínimos de solidaridad:}

Estas prestaciones se configuran como prestaciones de carácter asistencial, periódicas y temporales, gestionadas directamente por las Administraciones públicas, con el objetivo de contribuir a la satisfacción de las necesidades más elementales de los ciudadanos. Según GARCÉS SANAGUSTÍN, el receptor de la renta mínima de inserción es, a la vez «titular de un derecho a una prestación económica y beneficiario de un servicio social» ${ }^{156}$.

Esta prestación está sujeta al cumplimiento de ciertos requisitos por parte de los beneficiarios, entre los cuales, además de la carencia de recursos, se encuentra el residir en la Comunidad Autónoma respectiva y la firma de un compromiso de inserción laboral ${ }^{157}$. No obstante, se trata tanto de prestaciones subsidiarias, pues la misma será otorgada siempre que no se tenga derecho a otra prestación correspondiente de otros sistemas de protección social, como prestaciones complementarias, pues se otorgan hasta los importes que le corresponda percibir a su titular de acuerdo a los ingresos de la unidad económica de convivencia ${ }^{158}$.

155 Vide: Ley 39/2006, de 14 de diciembre, de Promoción de la Autonomía Personal y Atención a personas en situación de Dependencia, arts. 17-20; ALONSO-OLEA GARGÍA, B., y MEDINA GONZÁLEZ, S. (2011): 143-147.

156 Vide GARCÉS SANAGUSTÍN, A. (2005): 445.

157 Vide: ALONSO SECO, J.M., y GONZALO GONZÁLEZ, B. (2000): 439-446; GARCÉS SANAGUSTÍN, A. (2005): 447-448 y 463-467.

158 Vide Ley 3/2007, de 16 de marzo, de Renta Básica de Inserción de la Región de Murcia, art. 4 . 


\section{El sometimiento de las entidades prestadoras de recursos a la actividad limitadora de la Administración pública}

No es frecuente que las entidades tutelares también sean entidades prestacionales, esto es, tutelen y ofrezcan al mismo tiempo recursos sociales. Mas bien todo lo contrario, las entidades tutelares deben velar por buscar los recursos adecuados a sus tutelados, por lo que deberán iniciar los procedimientos administrativos correspondientes a fin de convertir a las personas adultas en usuarios de los recursos anteriormente descritos.

La participación de la iniciativa privada en el ámbito social está prevista en el conjunto de $\mathrm{CAAA}^{159}$. Estas entidades prestacionales, bien pueden ser públicas o privadas, de iniciativa privada social o mercantil, y están sometidas al cumplimiento de ciertos requisitos jurídico-administrativos.

El primer requisito es el sometimiento de las mismas al régimen jurídico de autorizaciones administrativas ${ }^{160}$, comunicación previa ${ }^{161}$ y declaración responsable ${ }^{162}$, previstas por las normas reguladoras de acción social. Su otorgamiento que corresponde a la Administración de la Comunidad Autónoma ${ }^{163}$, tiene como finalidad ase-

${ }^{159}$ A modo de ejemplo, Vide: Ley 5/2009, de 30 de junio, de Servicios Sociales de Aragón, arts. 78-84; Ley 12/2008, de 5 de diciembre, de Servicios Sociales del País Vasco, art. 58 y ss.

160 Vide: PÉREZ GÁLVEZ, J.F. Creación y regulación de centros y establecimientos sanitarios: autorización, registro e inspección, Vol. II, Bosch, Barcelona, 2003, p. 192; GARCÍA DE ENTERRÍA, E. Curso de Derecho Administrativo, Civitas, Madrid, 2003, p. 136; LAGUNA DE PAZ, J.C. La autorización administrativa, Thomson-Civitas, Cizur Menor, 2006, p. 141; LÓPEZ FERNÁNDEZ, F.J. (2014): 270-308.

161 Vide PÉREZ GÁLVEZ, J.F. (2003): 192; MARTÍN-RETORTILLO BAQUER, S. "De la simplificación de la Administración Pública", Revista de Administración Pública, 147, (1998), p. 8; RIVERO ORTEGA, R. "Simplificación administrativa y administración electrónica: objetivos pendientes en la transposición de la Directiva de Servicios", Revista catalana de Dret Públic, 42, (2011), p. 118.

162 Vide: BAUZÁ MARTORELL, F.J. "Declaración responsable y comunicación previa. Consideraciones críticas del procedimiento administrativo a raíz de la Ley Ómnibus", Diario La Ley, 7419, (2010), p. 3; LOZANO CUTANDA, B. "Ley Ómnibus: silencio administrativo, declaración responsable y comunicación previa", Diario La Ley, 7339, (2010), pp. 5-6.

163 Vide Decreto 87/1996, de 20 de febrero, de la Consejería de Trabajo y Asuntos Sociales, por el que se regula la autorización, registro, acreditación e inspección de los Servicios Sociales en Andalucía, modificado por el Decreto 102/2000, de 15 de marzo y el Decreto 153/2011, de 10 de mayo. En esta Comunidad Autónoma, el régimen jurídico de autorizaciones administrativas o comunicaciones es el siguiente: a) Autorización administrativa previa de creación o construcción; b) Autorización administrativa de funcionamiento; c) Autorizaciones administrativas en el ámbito sanitario; d) Autorización administrativa de modificación sustancial; e) Autorización administrativa o comunicación previa de cambio de titularidad; f) Autorización administrativa o comunicación previa de cambio de denominación; g) Autorización administrativa o comunicación previa de cese o cierre del recurso social. 
gurar el cumplimiento de los requisitos de calidad y de los estándares mínimos establecidos por las normas reguladoras de acción social para cada una de las actividades a desarrollar ${ }^{164}$. Estos requisitos han sido desarrollados por el conjunto de CCAA, a fin de establecer las condiciones materiales y funcionales mínimas que han de cumplir los centros y servicios sociales ofertados ${ }^{165}$.

El segundo requisito es la acreditación administrativa ${ }^{166}$, en el que se comprueba que las entidades reúnen los requisitos necesarios conforme a las exigencias y criterios de calidad ${ }^{167}$ fijadas en las disposiciones reglamentarias ${ }^{168}$. Entre sus caracteres destaco $^{169}$ : A) Se trata de un acto de carácter voluntario; b) Los criterios y estándares están previamente establecidos (carácter reglado); c) Existe un procedimiento de verificación llevado a cabo por los servicios de inspección de la Administración pública; d) Es necesario una resolución favorable de la Administración para su concesión; e) Es requisito para la obtención de subvenciones públicas y el establecimiento de conciertos administrativos ${ }^{170}$; f) En este procedimiento se tienen en cuenta aspectos relacionados con la ratio de personal, la implantación de sistemas de calidad, etc.

El tercer requisito es la obligación de que las entidades prestacionales y los recursos que ofrecen estén inscritos en el Registro de Entidades, Centros y Servicios Sociales de la Comunidad Autónoma. Estos registros están gestionados por la Administración pública ${ }^{171} \mathrm{y}$, por tanto, es un registro de naturaleza pública ${ }^{172}$. Además es requisito estar inscrito para la obtención de subvenciones públicas, por lo que las enti-

${ }^{164}$ Vide LÓPEZ FERNÁNDEZ, F.J. (2014): 247-268.

${ }^{165}$ A modo de ejemplo, Vide: Decreto 111/1992, de 26 de mayo, de la Diputación General de Aragón, por el que se regulan las condiciones mínimas que han de reunir los servicios y establecimientos sociales especializados, art. 4.b); Decreto 69/2005, de 3 de junio, del Consejo de Gobierno, que establece las condiciones mínimas que han de reunir los centros residenciales para personas de titularidad pública o privada de la Región de Murcia, Anexo I.

166 Vide LÓPEZ FERNÁNDEZ, F.J. (2014): 309-316.

167 Vide: Ley 16/2010, de 20 de diciembre, de Servicios Sociales de Castilla y León, art. 49.3; Ley 13/2008, de 3 de diciembre, de Servicios Sociales de Galicia, art. 49.

168 Vide Ley 7/2009, de 22 de diciembre, de Servicios Sociales de La Rioja, art. 72.

169 Vide PÉREZ GÁLVEZ, J.F. (2003): 199.

170 Vide Decreto 43/2011, de 17 de mayo, de la Consejería de Bienestar Social y Vivienda, por el que se aprueba el Reglamento de Autorización, Acreditación, Registro e Inspección de Centros y Servicios Sociales del Principado de Asturias, art. 17.

171 Vide Ley 14/2010, de 16 de diciembre, de Servicios Sociales de Castilla La Mancha, art. 41.c).

172 Vide Decreto 66/1999, de 4 de junio, de la Consejería de la Presidencia, por el que se aprueba el Reglamento Regulador del Sistema Balear de Servicios Sociales, art. 26.1. 
dades tutelares deberán también estar inscritas en el caso de pretender solicitarlas. Su finalidad permite conocer con exactitud las entidades y recursos existentes, por lo que es un eficiente instrumento de planificación y de publicidad ${ }^{173}$. Los datos registrales ${ }^{174}$ que se inscriben tienen que ver con la denominación de la entidad, de los recursos, las autorizaciones concedidas, etc., y el procedimiento de inscripción puede iniciarse de oficio o a instancia de parte ${ }^{175}$.

El cuarto requisito supone el sometimiento de las entidades prestacionales a la función inspectora de la Administración pública. A través de esta potestad, la Administración intenta asegurar el cumplimiento de las normas jurídicas ${ }^{176} \mathrm{y}$, por tanto, proteger la seguridad, salud y bienestar de los ciudadanos. La inspección tiene una doble función ${ }^{177}$, tanto preventiva, a través de la comprobación de las condiciones materiales y funcionales exigidas por las normas reguladoras de acción social sobre autorizaciones administrativas, como protectora ${ }^{178} \mathrm{y}$, en consecuencia, de vigilancia y control, a posteriori, sobre el mantenimiento de dichas condiciones y comprobación en los casos de comunicaciones previas y declaraciones responsables. Se trata de una función pública desarrollada por los inspectores de servicios sociales a través de visitas de inspección ${ }^{179}$, requerimientos, entrevistas, encuestas, etc.

Finalmente, las leyes de acción social establecen un régimen sancionador para el caso de que las entidades prestacionales incumplan las normas reguladoras de acción social $^{180}$. A este régimen es de aplicación los principios del orden penal que se encuentran regulados en la Ley 30/1992, de 26 de noviembre, del Régimen jurídico de las Administraciones públicas y del Procedimiento Administrativo Común, como el de legalidad, irretroactividad, tipicidad, responsabilidad y $\operatorname{proporcionalidad}^{181}$. Las

173 Vide: SANTAMARÍA PASTOR, J.A. Principios de Derecho Administrativo General II, Iustel, Madrid, 2006, p. 254; Ley 5/2009, de 30 de junio, de Servicios Sociales de Aragón, art. 82.1.

174 Vide Orden de 29 de febrero de 1996, de la Consejería de Trabajo y Asuntos Sociales, por la que se regula el Registro de Entidades, Servicios y Centros de Servicios Sociales en Andalucía, art. 4 .

175 Vide MORENO REBATO, M. (2002): 257.

176 Vide RIVERO ORTEGA, R. El Estado vigilante, Tecnos, Madrid, 2000, p. 25.

177 Vide FERNÁNDEZ RAMOS, S. La actividad administrativa de inspección, Comares, Granada, 2002, pp. 21-29.

178 Vide Decreto 396/2008, de 24 de junio, de la Consejería para la Igualdad y Bienestar Social, por el que se aprueba el Reglamento de Organización y Funcionamiento de la Inspección de Servicios Sociales de la Junta de Andalucía, art. 5.a).

179 Vide SOLER FIÉRREZ, E. La visita de inspección, Ed. La Muralla S.A., Madrid, 2002, pp. 27-28.

${ }^{180}$ Entre otras, Vide Ley 1/2003, de 24 de febrero, de Servicios Sociales del Principado de Asturias, art. 52.a).

${ }^{181}$ Vide: STG 21/01/1987; STG 21/01/1988; STC 06/02/1989; STS 21/09/1981. 
infracciones administrativas reguladas pueden provenir tanto de las entidades prestacionales como de los propios usuarios de los recursos. Estas infracciones se gradúan en leves, graves y muy graves y pueden consistir en multas económicas, apercibimientos y otras medidas accesorias, como inhabilitaciones para celebrar conciertos administrativos, acceso a financiación pública o el ejercicio de cargos de dirección ${ }^{182}$, entre otros. En algunas CCAA lo recaudado por sanciones económicas se destina a la mejora y cobertura de los recursos sociales ${ }^{183}$.

\section{CONSIDERACIONES FINALES}

En esta investigación se ha constatado la importante labor que desempeña la Administración pública en la protección de ciertos colectivos con necesidades sociales, como es el caso de las personas adultas. También hemos visto la importante variedad de relaciones jurídicas existentes en este ámbito, pues junto a la Administración pública y las personas adultas, éstas últimas como sujetos pasivos de dicha intervención, también aparecen las entidades tutelares y las entidades prestacionales de recursos sociales, que con funciones distintas concurren como sujetos de derechos y obligaciones recíprocamente.

Se ha verificado la trascendente doble función con la que la Administración pública interviene sobre las personas incapacitadas judicialmente: por un lado, mediante el ejercicio de las diferentes funciones tutelares establecidas por el Código Civil, ya sea por sí misma o mediante la promoción de determinadas entidades tutelares y, por otro lado, mediante la provisión de un variado catálogo de recursos sociales a fin de paliar y proteger socialmente las necesidades de un colectivo especialmente vulnerable como las personas adultas.

No obstante, se ha constatado que si bien las CCAA han adoptado una regulación específica en torno a su protección personal y patrimonial, mediante las instituciones señaladas anteriormente y la creación de entidades tutelares específicas, su acceso al sistema público de servicios sociales necesita de su equiparación con otras instituciones jurídico-administrativas propias de la acción social, como las personas con discapacidad y las personas en situación de dependencia, pues sólo una vez tramitados los correspondientes procedimientos administrativos y resueltos estos de forma favorable, se convierten en titulares de derechos y obligaciones.

182 Vide: Ley 5/2009, de 30 de junio, de Servicios Sociales de Aragón, art. 94.5; Ley 12/2007, de 11 de octubre, de Servicios Sociales de Cataluña, art. 99.2.

${ }^{183}$ Vide Ley 5/2009, de 30 de junio, de Servicios Sociales de Aragón, art. 100. 
Finalmente, se ha comprobado que toda intervención pública o privada en este ámbito requiere el cumplimiento de los requisitos jurídico-administrativos que exigen las normas reguladoras de acción social, por lo que la Administración pública se erige como responsable no sólo de ofrecer recursos sociales de calidad sino de velar porque las entidades prestacionales los gestionen con las mismas garantías que se presumen de aquélla.

\section{BIBLIOGRAFÍA}

ALEMÁN BRAGHO, C. El sistema público de de servicios sociales, Impredisur, Granada, 1991.

"La planificación en las leyes de servicios sociales", Revista de la Facultad de Derecho de la Universidad de Granada, 14, (1987).

ALEMÁN BRACHO, G., ALONSO SECO, J.M., y GARCÍA SERRANO, M. Servicios sociales públicos, Tecnos, Madrid, 2011.

ALONSO-OLEA GARCíA, B., y MEDINA GONZÁLEZ, S. Derecho de los Servicios Públicos Sociales, Civitas, Cizur Menor, 2011.

ALONSO SECO, J.M. y GONZALO GONZÁLEZ, B. La Asistencia Social y los Servicios Sociales en España, Ministerio de la Presidencia, Madrid, 2000.

ALONSO SECO, J.M., y FERNÁNDEZ SANTIAGO, P. "El sistema público de servicios sociales", en ALEMÁN BRACHO, G., (Coord.), Fundamentos de servicios sociales, Tirant Lo Blanch, Valencia, 2010.

ALONSO SECO, J.M. "El status jurídico-administrativo del interno en centros de la red pública asistencial: derechos y obligaciones", Documentación Administrativa, 271-272, (2005).

ANDRÉS SAÉNZ DE SANTA MARÍA, P. "La Carta de los Derechos Fundamentales de la Unión Europea en la práctica española", Revista de Derecho de la Unión Europea, 15, (2008).

ANGUAS ORTIZ, L.F. "El sistema para la autonomía y atención a la dependencia en la Comunidad Autónoma de Andalucía”, en FERNÁNDEZ RAMOS, S., y PÉREZ MONGUIÓ, J.M., (Coord.), El Derecho de los servicios sociales en Andalucía, Instituto Andaluz de Administración Pública, Sevilla, 2012.

ARENAL, C. La beneficencia, la filantropia y la caridad, Imprenta del Colegio de Sordomudos y de Ciegos, Madrid, 1861.

ARIAS MIRANDA, J. Reseña histórica de la beneficencia española, Imprenta del Colegio de Sordomudos y Ciegos, Madrid, 1862.

AZNAR LÓPEZ, M. "En torno a la beneficencia y su régimen jurídico", Revista española de Derecho Administrativo, 92, (1996).

BARRANCO VELA, R. "El principio de participación en las Leyes de Servicios Sociales", Alternativas: Cuadernos de Trabajo Social, (1993).

"Reflexiones y comentarios en torno a la contribución de los usuarios en el 
costo y mantenimiento de determinadas prestaciones en la Ley de Servicios Sociales de Andalucía", Revista andaluza de Trabajo y Bienestar Social, 32, (1994).

BARRERO RODRÍGUEZ, C. "Algunas consideraciones sobre los fines de las fundaciones y su garantía por la Administración”, Revista andaluza de Administración Pública, 183, (2000).

BAUZÁ MARTORELL, F.J. "Declaración responsable y comunicación previa. Consideraciones críticas del procedimiento administrativo a raíz de la Ley Ómnibus", Diario La Ley, 7419, (2010).

BELTRÁN AGUIRRE, J.L. El Régimen jurídico de la acción social pública, Instituto vasco de Administración Pública, Bilbao, 1992.

CASADO, D. Introducción a los Servicios Sociales, Acebo, Madrid, 1991.

CASTILLO BLANCO, F., y BARRANCO VELA, R. Competencias locales en materia de servicios sociales. Marco jurídico competencial en la actividad prestacional, CEMCI, Granada, 1994.

CASTILLO BLANCO, F. "El empleo público: distribución de competencias, regulación y clases de empleados", en CANO CAMPOS, T., (Coord.), Lecciones y materiales para el estudio del Derecho administrativo, Iustel, Madrid, Vol. 2, 2009.

COSTA, J.P. "La Carta Social Europea", en MUÑOZ MACHADO, S., GARCÍA DELGADO J.L., y Luis GONZÁLEZ SEARA, L. (directores), Las estructuras del bienestar en Europa, Escuela Libre Editorial, Madrid, 2000.

DE LORENZO GARGIA, R., y CABRA DE LUNA, M.A. "Las fundaciones", en AA.VV., El sector no lucrativo en España, Escuela Libre Editorial, Madrid, 1993.

DE LORENZO GARCÍA, R., y PALACIOS, A. "Los grandes hitos de la protección jurídica de las personas con discapacidad en los albores del siglo XXI", Documentación Administrativa, 271-272, (2005).

DE PALMA DEL TESO, A. "El contrato asistencial de Derecho administrativo. Los servicios sociales de atención a la tercera edad en Cataluña", Revista jurídica de Cataluña, 3, (2000).

EZQUERRA HUERVA, A. "El estatuto jurídico de los usuarios de centros y establecimientos de servicios sociales", en EZQUERRA HUERVA, A. Ciudadanos y prestaciones sociales residenciales, Iustel, Madrid, 2011.

FERNÁNDEZ RAMOS, S. La actividad administrativa de inspección, Comares, Granada, 2002.

"La ordenación general de los servicios sociales en Andalucía: situación actual y prospectiva”, en FERNÁNDEZ RAMOS, S., y PÉREZ MONGUIÓ, J.M., (Coord.), El Derecho de los Servicios Sociales en Andalucía, Instituto Andaluz de Administración Pública, Sevilla, 2012.

GARCÉS FERRER, J. Administración social pública. Bases para el estudio de los servicios sociales, Tirant Lo Blanch, 1992.

GARGÉS SANAGUSTÍN, A. La Acción Social: delimitación conceptual y régimen juridico, Diputación General de Aragón, Zaragoza, 1988. 
"Las prestaciones dinerarias: en particular, los ingresos mínimos de inserción y el debate sobre la renta básica", Documentación Administrativa, 271-272, (2005).

GARCÍA DE ENTERRÍA, E. Curso de Derecho Administrativo, Civitas, Madrid, 2003.

GARRIDO FALLA, F., y Otros, Tratado de Derecho Administrativo. Parte General: conclusión, Tecnos, Madrid, 2006.

GIL y GIL, J.L. "Los derechos sociales en la Carta de los Derechos Fundamentales de la Unión Europea", Cuadernos electrónicos de filosofia del derecho, 5, (2002).

GÓMEZ DE LA SERNA, P. Instituciones del Derecho Administrativo Español, Tomo II, Imprenta de D. Vicente de Zalama, Madrid, 1843.

GONZÁLEZ NAVARRO, F. Derecho Administrativo Español, EUNSA, Pamplona, 1994.

GUASP, J. Derecho, Imprenta Gráficas Hergón, Madrid, 1971.

HERRERA GÓMEZ, M. Los orígenes de la intervención estatal en los problemas sociales, Escuela Libre Editorial, Madrid, 1999.

JORDANA DE POZAS, J. "El movimiento asociativo y la asistencia social", en AA.VV., Problemas fundamentales de beneficencia y asistencia social, Ministerio de Gobernación, Madrid, 1967.

LAGUNA DE PAZ, J.C. La autorización administrativa, Thomson-Civitas, Cizur Menor, 2006.

LEMA TOMÉ, M., "La reforma sanitaria en España: especial referencia a la población inmigrante en situación administrativa irregular", Revista en Cultura de la Legalidad, 5, (2014).

LÓPEZ ALONSO, G. "La acción pública no estatal", en AA.VV., Historia de la Acción Social Pública en España. Beneficencia y previsión, Ministerio de Trabajo y Asuntos Sociales, 1990.

LÓPEZ FERNÁNDEZ, F.J. "La acción social en la Constitución española de 1812 y su posterior legalización a través de medidas de carácter público", Revista de la Asociación Internacional de Derecho Administrativo, 10, (2011).

"El papel de las entidades locales en el ámbito de la acción social en España", Revista del Instituto de Ciencias furídicas de Puebla, 32, (2013).

"Los gobiernos locales ante la exclusión social. Análisis del caso andaluz", El Consultor de los Ayuntamientos y de los fuzgados, 21, (2014).

Acción social en España (centros, servicios y establecimientos de servicios sociales), ACCI, Madrid, 2014.

LÓPEZ MENUDO, F. "Los derechos sociales en los Estatutos de Autonomía", Revista andaluza de Administración Pública, 73, (2009).

LOZANO CUTANDA, B. "Ley Ómnibus: silencio administrativo, declaración responsable y comunicación previa", Diario La Ley, 7339, (2010).

MARTÍN-RETORTILLO BAQUER, S. "De la simplificación de la Administración Pública", Revista de Administración Pública, 147, (1998). 
MARTÍNEZ ROMÁN, M.A., y GUILLÉN SÁDABA, E. "La reorientación de los servicios sociales en los 80", en GARCíA VILLALUENGA, L., (Coord.), El Derecho y los servicios sociales, Comares, Granada, 1997.

MIGUEZ MACHO, L. "La transformación del régimen jurídico de los servicios sociales", Revista española de Derecho Administrativo, 153, (2012).

MINISTERIO DE TRABAJO Y ASUNTOS SOCIALES, Libro Blanco. Atención a las personas en situación de dependencia en España, Subdirección General de Publicaciones del Ministerio, Madrid, 1997.

MORALES, J. "Estado social y privatizaciones", Cuadernos de Relaciones Laborales, 13, (1998).

MORENO MOLINA, A.M. "Las competencias de las entidades locales", en CASTILLO BLANCO, F., (Coord.), Modificaciones y panorama actual del régimen local español, Centro de Estudios Municipales y de Cooperación Internacional, Granada, 2000.

MORENO REBATO, M. Régimen jurídico de la Asistencia Social en España, Ministerio de Trabajo y Asuntos Sociales, Madrid, 2002.

MUÑOZ MACHADO, S., MESTRE DELGADO J.F., y ÁLVAREZ GARCÍA, V. "La europeización de las garantías de los derechos y la universalización en Europa de algunas políticas de bienestar", en MUÑOZ MACHADO, S., GARCÍA DELGADO, J.L., y GONZÁLEZ SEARA, L., (directores), Las estructuras del bienestar en Europa, Escuela Libre Editorial, Madrid, 2000.

NIETO, A. "La organización de las Administraciones públicas para el servicio del bienestar", en MUÑOZ MACHADO, S., GARCíA DELGADO, J.L., y GONZÁLEZ SEARA, L. (directores), Las estructuras del bienestar en Europa, Escuela Libre Editorial, Madrid, 2000.

ORTEGA ÁLVAREZ, L., y JIMÉNEZ BLANCO, A. "Los sujetos de la relación jurídico-administrativa", en PAREJO ALFONSO, L., (Coord.), Manual de Derecho Administrativo, Ariel Derecho, Barcelona, 1990.

PARADA VÁZQUEZ, R. Derecho Administrativo I. Parte General, Marcial Pons, Madrid, 2007.

PÉREZ CASTILLO, R., y OLMEDO AREAL, J.M. El procedimiento para el Reconocimiento de la situación de Dependencia: perspectivas de Desarrollo y de Futuro en el Marco del Estado de Bienestar Social en la Comunidad Autónoma Andaluza, Instituto Andaluz de Administración Pública, Sevilla, 2009.

PÉREZ GÁLVEZ, J.F. La Organización Nacional de Ciegos Españoles ONCE: (Corporación de derecho público, de carácter social), Fundación ONCE, Madrid, 2006. (2003).

"Administración sanitaria y telemedicina", Actualidad administrativa, 27,

Creación y regulación de centros y establecimientos sanitarios: autorización, registro e inspección, Vol. II, Bosch, Barcelona, 2003.

da, 2007.

Las agencias estatales para la mejora de los servicios públicos, Ed. Comares, Grana- 
PIÑAR MAÑAS, J.L. Régimen jurídico de las fundaciones: jurisprudencia del Tribunal Constitucional y del Tribunal Supremo, Ministerio de Asuntos Sociales, Madrid, 1993.

QUEREJETA GONZÁLEZ, M. Discapacidad/Dependencia: unificación de criterios de valoración y clasificación, Ministerio de Trabajo y Asuntos Sociales, Madrid, 2004.

RIVERO ORTEGA, R. El Estado vigilante, Tecnos, Madrid, 2000.

"Simplificación administrativa y administración electrónica: objetivos pendientes en la transposición de la Directiva de Servicios", Revista catalana de Dret Públic, 42, (2011).

SALAMERO TEIXIDÓ, L. "Los mecanismos de control como garantía de los derechos de los usuarios de centros y establecimientos de servicios sociales", en EZQUERRA HUERVA, A. Ciudadanos y prestaciones sociales residenciales, Iustel, Madrid, 2011.

SANTAMARÍA PASTOR, J.A. Principios de Derecho Administrativo General II, Iustel, Madrid, 2006.

SOLER FIÉRREZ, E. La visita de inspección, Ed. La Muralla S.A., Madrid, 2002.

TORNOS MAS, J. "Efectividad de los derechos y exigibilidad de los servicios sociales", Documentación Administrativa, 271-272, (2005).

TORRES LÓPEZ, M.A. "La gestión de la política de dependencia en la Comunidad Autónoma de Andalucía. La Agencia andaluza para la atención de la dependencia”, Revista andaluza de Administración Pública, 77, (2010).

La discapacidad en el Derecho Administrativo, Civitas Thomson Reuters, Cizur Menor, 2011.

VAQUER CABALLERÍA, M. La acción social (Un estudio sobre la actualidad del Estado social de Derecho), Tirant Lo Blanch, Valencia, 2002.

VILLAR ROJAS, F.J. "Formas de gestión de los servicios sociales. En particular, la vinculación de gestores privados al sistema público mediante conciertos y convenios", Documentación Administrativa, 27 1-272, (2005).

"Iniciativa privada y prestación de servicios sociales. Las redes o sistemas públicos de servicios sociales", en EZQUERRA HUERVA, A., (Coord.), El marco jurídico de los servicios sociales en España, Atelier, Barcelona, 2012. 